\title{
Organic Anion Transporting Polypeptide (OATP)1B1 and OATP1B3 as Important Regulators of the Pharmacokinetics of Substrate Drugs
}

\author{
Kazuya Maeda \\ Laboratory of Molecular Pharmacokinetics, Graduate School of Pharmaceutical Sciences, \\ The University of Tokyo; 7-3-1 Hongo, Bunkyo-ku, Tokyo 113-0033, Japan. \\ Received November 7, 2014
}

\begin{abstract}
Nobody doubts the importance of organic anion transporting polypeptide (OATP)1B1 and 1B3 in the clinical pharmacokinetics of substrate drugs. Based on the theory of pharmacokinetics, even if a drug is eliminated from the body by extensive metabolism, the rate-determining process of the hepatic intrinsic clearance of OATP substrates is often hepatic uptake. Because of their broad substrate specificities, once the functions of OATP1B1 or OATP1B3 are altered by several kinds of special occasions such as drug-drug interactions (DDI) and genetic polymorphisms of transporter genes, the hepatic clearance of many kinds of structurally-unrelated drugs is expected to be changed. In some cases, these alterations of pharmacokinetics lead to modified pharmacological effects and adverse reactions such as statin-induced myotoxicity and the glucose-lowering effect of anti-diabetes drugs. Thus, appropriate methods with which to quantitatively predict the changes in plasma and tissue concentrations of drugs are needed in the process of drug development. As for DDI, a static model that takes into consideration of the theoretically-maximum unbound inhibitor concentration is often used for the sensitive detection of possible DDI risks and this method has been adopted in several regulatory guidance/guidelines on DDI. Regarding genetic polymorphisms, the effects of $S L C O 1 B 1$ c.388A $>G$ and c.521T $>C$ on the pharmacokinetics of substrate drugs have been extensively investigated. Even though there are some discrepancies, c.521T $>C$ generally decreased hepatic uptake activity, while c.388A $>G$ tended to slightly increase it. This article briefly summarizes the current status of research on hepatic OATP1B1 and OATP1B3 and the clinical significance of their functions.
\end{abstract}

Key words organic anion transporting polypeptide; hepatocyte; genetic polymorphism; drug-drug interaction

\section{INTRODUCTION}

Organic anion transporting polypeptide (OATP)1B1 and $1 \mathrm{~B} 3$ belong to the OATP family consisting of 11 members in humans and have 12 putative membrane spanning domains. ${ }^{1)}$ Among them, OATP1B1 and OATP1B3 are almost exclusively expressed on the basal side of hepatocytes in normal human organs. In the liver, OATP1B1 is expressed uniformly, but OATP1B3 is abundantly expressed in the perivenous section. ${ }^{2)}$ From the viewpoint of species differences, hepatic OATP transporter isoforms are poorly conserved among species and no orthologs have been identified in preclinical species and humans. Oatpla1, Oatpla4 and Oatp1b2 are expressed in the rodent liver and Oatplb4 is expressed in canine liver. ${ }^{3)}$ Both OATP1B1 and OATP1B3 can accept a wide variety of structurally-unrelated compounds including clinically-used important drugs such as hydroxymethylglutaryl (HMG)-CoA reductase inhibitors (statins), angiotensin II receptor blockers (sartans), angiotensin converting enzyme (ACE) inhibitors, and anti-diabetes (glinides) as substrates. Though OATP transporters preferentially transport anionic compounds, neutral (e.g. digoxin, ouabain, lopinavir) and zwitter ionic (e.g. fexofenadine) compounds are also accepted by OATP1B1 and OATP1B3. Moreover, their substrate specificities often overlap each other, but estrone-3-sulfate can be preferentially recognized by OATP1B1 rather than OATP1B3, whereas cholecystokinin octapeptide (CCK-8), telmisartan, paclitaxel and docetaxel are specifically transported via OATP1B3, but not OATP1B1. Interestingly, most of the OATP substrates are often also substrates of multidrug-resistance associated protein (MRP)2, thus their efficient hepatobiliary transport is realized by the cooperative functions of OATP-mediated hepatic uptake and MRP2-mediated biliary efflux even though the protein sequence of OATPs is very different from that of MRP2. ${ }^{4)}$ As for endogenous substrates, previous reports indicated that bilirubin, a breakdown product of heme catabolism in hemoglobin of red blood cells, is a substrate of OATP1B1 and OATP1B3. ${ }^{5,6)}$ Via these transporters, bilirubin is efficiently taken up into hepatocytes and undergoes extensive glucuronidation by uridine 5'-diphosphate (UDP)-glucuronosyltransferases (UGTs) and subsequent biliary excretion of bilirubin glucuronide via MRP2. Recent reports indicated that lossof-function mutations in both SLCO1B1 and SLCO1B3 genes (encoding OATP1B1 and OATP1B3, respectively) result in the Rotor syndrome, one of the hereditary hyperbilirubinemias. ${ }^{7)}$

\section{DIFFERENT CONTRIBUTIONS OF OATP1B1 AND OATP1B3 TO THE HEPATIC UPTAKE OF OATP SUB- STRATES}

As indicated above, the substrate specificity of OATP1B1 overlaps that of OATP1B3 and OATP2B1, and thus a single compound is often recognized by multiple hepatic OATP transporters. To quantitatively predict the change of uptake clearance of substrates when the function of a certain OATP isoform is altered by various perturbations such as genetic polymorphisms and interacting drugs, the relative contribution of each OATP isoform to the overall hepatic uptake of 
(a)

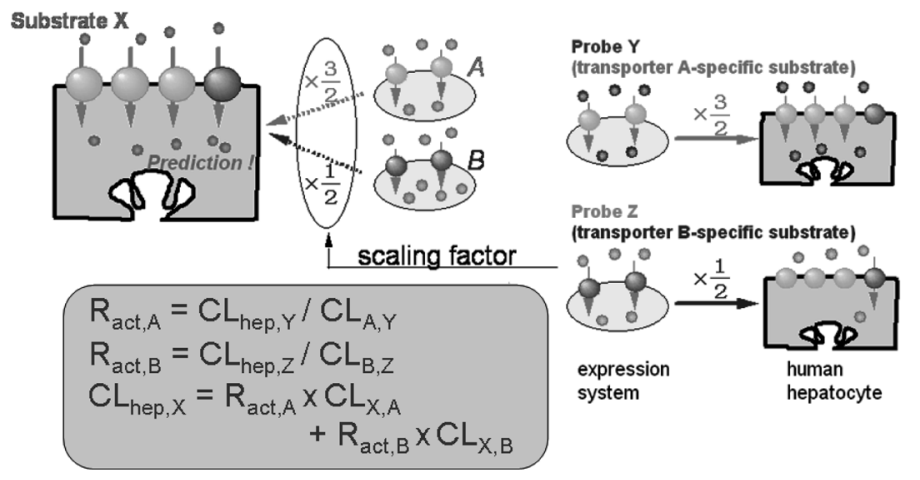

(c)

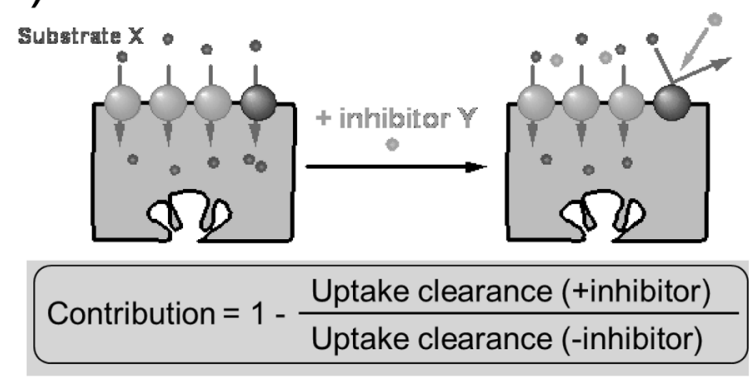

(b)

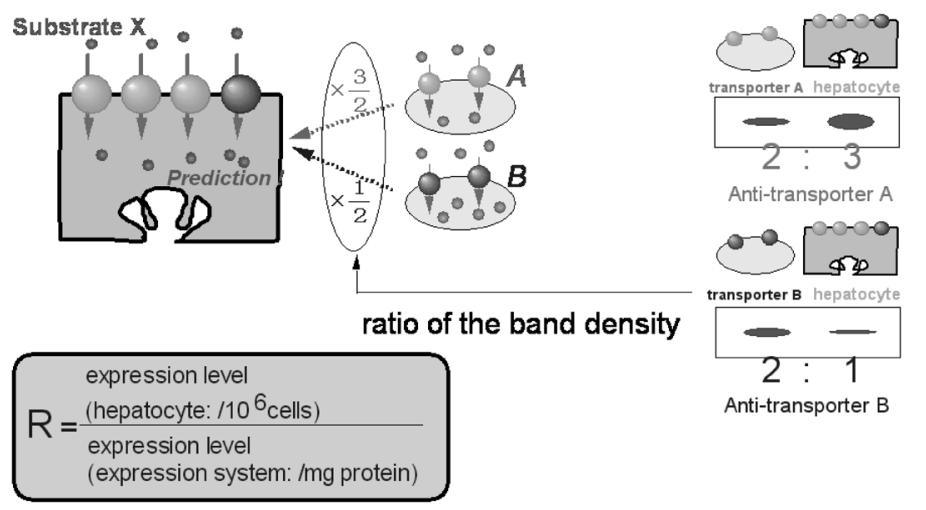

Fig. 1. Methodologies to Identify the Relative Contribution of Transporter Isoforms to the Overall Hepatic Uptake of Ligands ${ }^{8)}$

(a) RAF (relative activity factor) method using transporter isoform-selective substrates. (b) Determination of the relative expression levels of transporter isoforms by Western blot. (c) Inhibition of hepatic uptake by transporter isoform-selective inhibitors.

substrates is essential information. Even if the transport activity of a compound in isoform $\mathrm{X}$-expressing recombinant cells is much more than that in isoform Y-expressing cells, we can never ascertain the relative importance of isoform $\mathrm{X}$ and $\mathrm{Y}$ in its uptake into human hepatocytes since information about the relative expression levels of $\mathrm{X}$ and $\mathrm{Y}$ in expression systems and intact hepatocytes is lacking and it is difficult to tightly adjust the protein expression level of exogenously expressed gene at the moment. Based on such a situation, we created some methodologies to quantify the relative contribution of OATPs to the hepatic uptake of substrate drugs. ${ }^{8)}$ The first approach is to compare the transport activities of isoform-selective substrates and test compounds in gene expression systems and human hepatocytes ${ }^{9)}$ (Fig. 1(a)). The basic concept of this approach was originally derived from the relative activity factor (RAF) method in the field of metabolic enzymes. ${ }^{10)}$ In principle, the ratio of the transport activity of a specific substrate for a single isoform in human hepatocytes to that in the gene expression system should correspond to the ratio of the protein expression level of functional transporter between human hepatocytes and the gene expression system. Once that ratio was obtained for each isoform, by multiplying the transport activity of a test compound in the gene-expression system by that ratio, its uptake clearance mediated by a specific isoform can be estimated. Using this approach, we attempted to discern the relative contribution of OATP1B1 and OATP1B3 to the hepatic uptake of drugs. Between OATP1B1 and OATP1B3, estrone-3-sulfate (E-sul) and cholecystoki- nin octapeptide (CCK-8) can be regarded as OATP1B1- and OATP1B3-selective probe substrates, respectively. The transport activity $\left[C L_{\text {uptake }}\right]$ of E-sul, CCK-8 and a test compound was first measured in human hepatocytes and OATP1B1- and OATP1B3-expression systems and the following calculations were executed.

$$
\begin{aligned}
& \text { Ratio }_{1 \mathrm{~B} 1}==\frac{C L_{\text {uptake, E-sul, hep }}}{C L_{\text {uptake, E-sul, 1B1 }}} \\
& \text { Ratio }_{1 \mathrm{~B} 3}=\frac{C L_{\text {uptake, CCK-8, hep }}}{C L_{\text {uptake, } \mathrm{CCK}-8,1 \mathrm{~B} 3}}
\end{aligned}
$$

If the test compound is taken up into hepatocytes only via OATP1B1 and OATP1B3, the following equation must hold true.

$$
C L_{\text {hep,test }}=\text { Ratio }_{1 \mathrm{~B} 1} \times C L_{\text {uptake,test, } 1 \mathrm{~B} 1}+\text { Ratio }_{1 \mathrm{~B} 3} \times C L_{\text {uptake,test,1B3 }}
$$

In the case of pitavastatin, it is a good substrate of both OATP1B1 and OATP1B3 in an in vitro uptake assay using OATP1B1- and OATP1B3-expressing HEK293 cells. However, in human hepatocytes, the contribution of OATP1B1 to the hepatic uptake of pitavastatin was estimated to be more than $90 \%$ from our calculations and the sum of OATP1B1- and OATP1B3-mediated uptake clearances of pitavastatin is almost comparable to that in human hepatocytes, which suggested that pitavastatin uptake can be mainly explained by the func- 


\section{OATP1B1 OATP1B3}

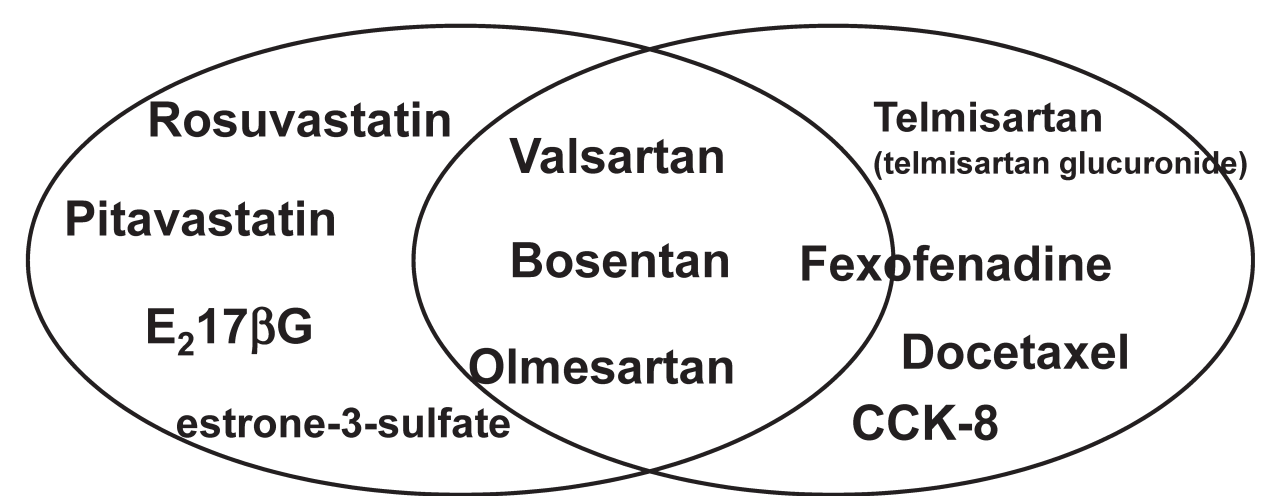

Fig. 2. Different Relative Contribution of OATP1B1 and OATP1B3 to the Overall Hepatic Uptake of Various OATP Substrates

tions of OATP1B1 and OATP1B3 in the human liver. ${ }^{9)}$ In this approach, the selectivity of probe substrates is critical. Since OATP2B1 is also expressed in human hepatocytes and E-sul is also a substrate of OATP2B1, hepatic uptake of E-sul may be mediated not only by OATP1B1, but also by OATP2B1. Thus, to verify our result, another approach was also used to determine the contributions of OATP1B1, 1B3 and 2B1 by directly measuring the relative expression levels of these transporters in human hepatocytes and gene expression systems with Western blot analysis ${ }^{11}$ (Fig. 1(b)). The principle of this approach is the same as the previous one using isoform-selective probe substrates. It was found although pitavastatin is also recognized by OATP2B1 as a substrate, by considering the relative expression levels of these three OATP isoforms in hepatocytes and expression systems, the contribution of OATP2B1 was considered to be minor compared with that of OATP1B1. As for sartans, both valsartan and telmisartan have anionic moieties and are efficiently taken up into hepatocytes. In our in vitro uptake assay using a gene expression system, valsartan is a substrate of both OATP1B1 and OATP1B3 and our RAF method revealed that the relative contribution of OATP1B1 and OATP1B3 to its hepatic uptake is almost the same, though the result shows a large variation depending on the batch of human hepatocytes. ${ }^{12)}$ On the other hand, interestingly, telmis$\operatorname{artan}$ is recognized only by OATP1B3, but not OATP1B1. ${ }^{13)}$ To further confirm this result, we created a third approach using an isoform-selective inhibitor ${ }^{13)}$ (Fig. 1(c)). Between OATP1B1 and OATP1B3, although no good OATP1B3-selective inhibitors have been identified, E-sul can also be a selective inhibitor for OATP1B1. Thus, the contribution of OATP1B1 to the hepatic uptake of compounds can also be estimated as an inhibitable portion of E-sul in their hepatic uptake. In our experiment, hepatic uptake of estradiol-17 $\beta$-glucuronide, which is taken up into hepatocytes predominantly via OATP1B1 from the RAF analyses, was significantly inhibited by E-sul, whereas that of telmisartan was not altered by E-sul. ${ }^{13)}$ This approach is very easy to take, but since our experiences suggested that E-sul sometimes cannot inhibit the OATP1B1-mediated uptake of some substrates, it is recommended to check whether E-sul did in fact inhibit the uptake of substrates in OATP1B1-expressing cells beforehand. Each method has some advantages and disadvantages compared with other methods, thus the relative contribution of each isoform must be confirmed by multiple approaches. Through these approaches, we have determined the contribution of OATP1B1 and OATP1B3 to the hepatic uptake of various substrate drugs and these results indicated that the molecular mechanisms of the hepatic uptake depend on individual substrates even if they are recognized by both OATP1B1 and OATP1B3 as substrates and efficiently taken up into hepatocytes (Fig. 2).

\section{OATP1B1 AND OATP1B3 AS DETERMINANTS OF HEPATIC CLEARANCE OF SUBSTRATE DRUGS}

When considering the prediction of in vivo hepatic clearance from in vitro experiments, if drugs are extensively metabolized by hepatic enzymes such as CYP, in the conventional approach, in vitro metabolic clearance of drugs is measured with human liver microsomes and it is simply scaled up by multiplying the intrinsic metabolic clearance obtained from in vitro experiments by the physiological scaling factors such as the amount of total protein in microsomal fraction per unit liver weight and total liver weight per unit kilogram body weight. Using these approaches, several previous papers succeeded in the accurate prediction of in vivo hepatic clearance of several drugs from in vitro data. ${ }^{14,15)}$ However, looking into these data, though overall prediction accuracy of multiple drugs was fairly good within the range of 2- to 3-fold differences between the observed and predicted clearances, the hepatic clearances of some drugs could still not be accurately predicted from in vitro metabolism assays. One of the possible reasons for such discrepancy is the involvement of membrane transporters in the hepatic uptake of drugs. For example, some types of statins (e.g. pitavastatin, pravastatin, rosuvastatin) and sartans (e.g. valsartan, olmesartan) are thought not to undergo metabolism, but to be efficiently excreted into bile in an unchanged form in humans. In this case, it is natural to wrongly estimate the in vivo hepatic clearance from in vitro metabolic intrinsic clearance. Moreover, recently, several kinds of drugs, which are eliminated from the body by extensive metabolism, were found to be a substrate of hepatic uptake transporters like OATP1B1 and OATP1B3 (Table 1). For these drugs, in vivo hepatic clearance can be dominated not only by the metabolic activity, but also by the hepatic uptake activity, so metabolic intrinsic clearance is not always equal to the overall hepatic intrinsic clearance. Let us consider the impact of the function of metabolic enzymes and uptake 
Table 1. Examples of Dual Substrates of Hepatic OATPs and Metabolic Enzymes

\begin{tabular}{lcc}
\hline \hline & Uptake transporter & Metabolic enzyme \\
\hline Atorvastatin & OATPs & CYP3A4 \\
Cerivastatin & OATPs & CYP2C8, (3A4) \\
Fluvastatin & OATPs & CYP2C9 \\
Repaglinide & OATPs & CYP2C8, 3A4 \\
Nateglinide & OATPs & CYP2C9, 3A4 \\
Glibenclamide & OATPs & CYP2C9, 3A4 \\
Lopinavir & OATP1B1 & CYP3A4 \\
Atrasentan & OATPs & UGTs \\
Bosentan & OATPs & CYP2C9, 3A4 \\
Telmisartan & OATP1B3 & UGTs \\
Torasemide & OATPs & CYP2C9 \\
Simeprevir & OATPs & CYP3A4 \\
\hline
\end{tabular}

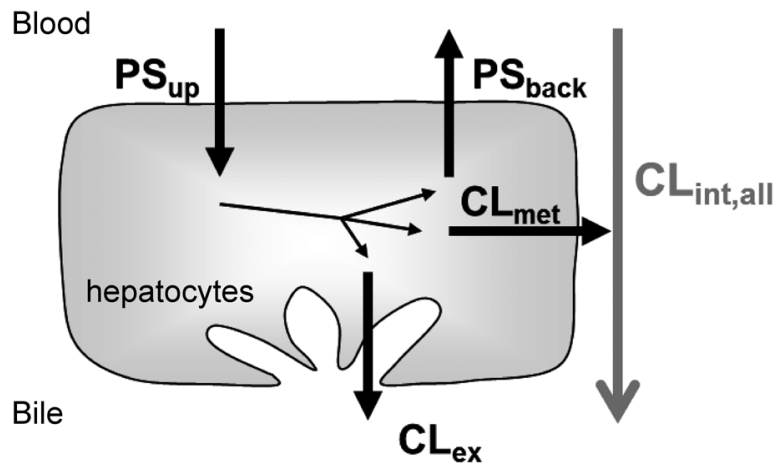

Fig. 3. Scheme of the Multiple Processes Constituting Overall Hepatic Intrinsic Clearance

transporters on the hepatic clearance of drugs from the pharmacokinetic theory. ${ }^{16,17)}$

As shown in Fig. 3, the overall hepatic intrinsic clearance of drugs $\left[C L_{\text {int,all }}\right]$ can be separated into various elementary processes. At first, drugs in the blood must be taken up into hepatocytes via both passive diffusion and transportermediated transport $\left[P S_{\text {up }}\right]$. Next, drugs in the hepatocytes undergo one of three different fates; (1) backflux to the blood via passive diffusion and sometimes active transport via ATP binding cassette (ABC) type of transporters such as multidrug resistance-associated protein (MRP)3 and MRP4 $\left[P S_{\text {back }}\right]$, (2) excretion into bile in an unchanged drug via transporters such as P-glycoprotein (P-gp), MRP2 and breast cancer resistance protein (BCRP) $\left[P S_{\mathrm{ex}}\right]$ and (3) intrahepatic metabolism by various metabolic enzymes $\left[C L_{\text {met }}\right]$. The overall hepatic intrinsic clearance can be described by the intrinsic clearance for each process as shown below.

$$
C L_{\text {int, all }}=P S_{\text {up }} \times \frac{P S_{\mathrm{ex}}+C L_{\mathrm{met}}}{P S_{\mathrm{back}}+P S_{\mathrm{ex}}+C L_{\mathrm{met}}}
$$

Based on this equation, if the sum of $P S_{\mathrm{ex}}$ and $C L_{\mathrm{met}}$ (clearance contributing to the elimination of drugs from the body) is much larger than $P S_{\text {back }}$, Eq. 4 can approximate the following equation.

$$
C L_{\text {int, all }} \sim P S_{\text {up }}
$$

This means that overall hepatic intrinsic clearance can be described only by the uptake intrinsic clearance, but not by metabolic intrinsic clearance. In other words, the rate-limiting step of hepatic clearance is the hepatic uptake process. Under such a situation, even if drugs are extensively metabolized by metabolic enzymes, in vitro metabolic clearance in liver microsomes is not a good predictor of hepatic clearance and hepatic uptake clearance estimated with human hepatocytes should be needed for its accurate prediction. On the other hand, if $P S_{\text {back }}$ is much larger than $P S_{\mathrm{ex}}+C L_{\mathrm{met}}$, Eq. 4 can be approximately transformed into the following equation.

$$
C L_{\text {int,all }}=P S_{\text {up }} \times \frac{P S_{\mathrm{ex}}+C L_{\mathrm{met}}}{P S_{\text {back }}}
$$

In this case, when predicting $C L_{\text {int,all }}$, intrinsic clearances for all the processes must be needed. If drugs are not substrates of hepatic uptake transporters and protein-unbound drugs easily pass through the lipid bilayer due to their lipophilicity, $P S_{\text {up }}$ is considered to be identical to $P S_{\text {back }}$ and $P S_{\text {back }}$ is much larger than $P S_{\mathrm{ex}}+C L_{\mathrm{met}}$. Under this condition, Eq. 4 can be transformed as follows.

$$
C L_{\text {int, all }}=P S_{\mathrm{ex}}+C L_{\mathrm{met}}
$$

Thus, if drugs are extensively metabolized in the liver and no parent compounds are excreted into bile $\left[P S_{\mathrm{ex}} \mathrm{ca}\right.$. 0], the traditional in vitro method of hepatic clearance prediction with human liver microsomes can be effective.

As discussed above, the second term of Eq. 4 is an important parameter to show the rate-determining process of $C L_{\text {int,all }}$, thus we sometimes define the parameter named " $\beta$ value" as shown below.

$$
\begin{gathered}
\beta=\frac{P S_{\mathrm{ex}}+C L_{\mathrm{met}}}{P S_{\mathrm{back}}+P S_{\mathrm{ex}}+C L_{\mathrm{met}}} \\
C L_{\mathrm{int}, \mathrm{all}}=P S_{\mathrm{up}} \times \beta
\end{gathered}
$$

This indicates that $C L_{\text {int,all }}$ can approximate $P S_{\text {up }}$ if $\beta$ becomes close to 1. Watanabe et al. demonstrated that in vivo hepatic clearances of 12 OATP substrates in rats show a good oneto-one correlation with their uptake clearances obtained from the integration plot approach and in vitro uptake clearances estimated with isolated rat hepatocytes. ${ }^{18)}$ This suggests that the $\beta$ values of these tested compounds are close to 1 and OATP-mediated hepatic uptake is a rate-determining process of hepatic intrinsic clearance in rats. This is also implied in humans by a one-to-one correlation between in vivo non-renal clearances of 9 OATP substrates in humans and the predicted clearances from in vitro uptake assay with human cryopreserved hepatocytes. ${ }^{19)}$ Regarding statins, Watanabe et al. have demonstrated that the overall hepatic clearance of 4 statins, pitavastatin, rosuvastatin, atorvastatin and fluvastatin is mainly dominated by the hepatic uptake process. ${ }^{20)}$ Pitavastatin and rosuvastatin are not metabolized in rats and mainly excreted into bile in an unchanged form, whereas atorvastatin and fluvastatin, which are both reported to be OATP substrates, are extensively metabolized by CYP3A4 and CYP2C9, respectively. In vivo hepatic clearances of these statins were well correlated with in vitro uptake intrinsic clearances obtained with isolated hepatocytes, but poorly correlated with in vitro metabolic intrinsic clearances obtained with liver microsomes. This 
(a)

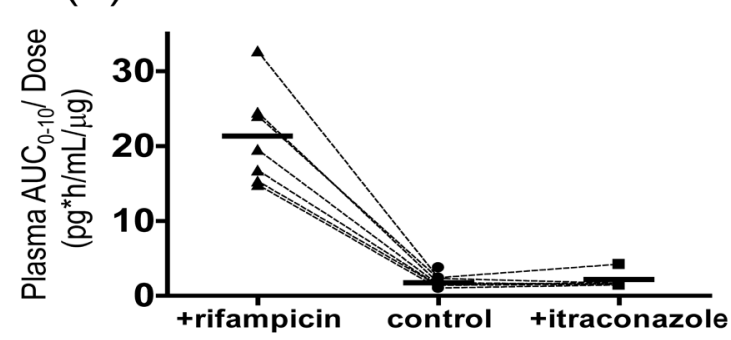

(b)

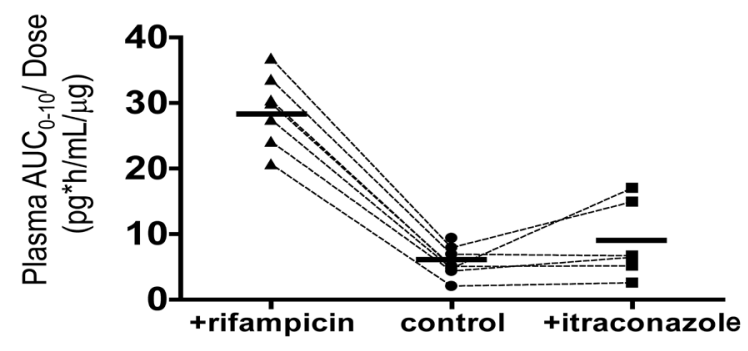

(c)

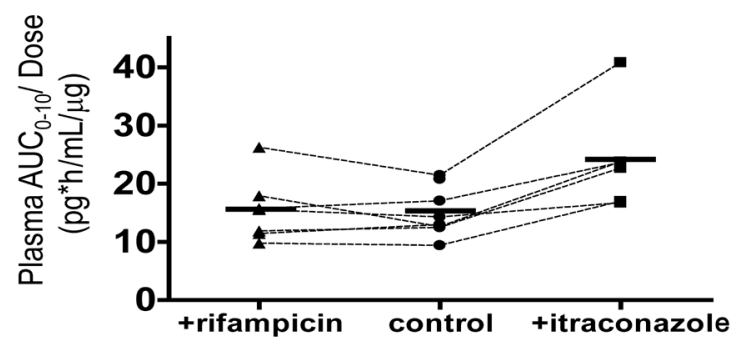

(d)

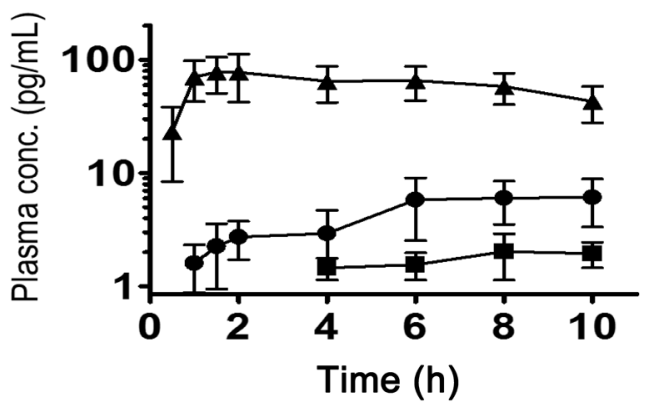

Fig. 4. (a-c) Effects of Oral Administration of Rifampicin and Intravenous Administration of Itraconazole on the Dose-Normalized Plasma AUCs of Atorvastatin (a), Pravastatin (b), and Midazolam (c), (d) Plasma Concentration of 1-Hydroxyatorvastatin in the Presence of Rifampicin (Triangle), or Itraconazole (Square), or in Its Absence (Circle)

These graphs are cited from ref. 21.

result suggested that the uptake process mainly determines the overall hepatic clearances of these statins even if they are eliminated from the body by extensive metabolism. We further tried to show the rate-limiting step of hepatic clearance of OATP substrates directly in vivo in humans by a cocktail microdosing clinical study. ${ }^{21)}$ In this study, atorvastatin was selected as a model compound since it is a substrate of both OATPs and CYP3A4. In the first period, a cocktail of microdose (each $33 \mu \mathrm{g}$ ) of atorvastatin, pravastatin (OATP1B1 probe substrate) and midazolam (CYP3A4 probe substrate) was administered to healthy volunteers and the plasma concentrations of these drugs were monitored. Then, in the second and third periods, an oral single dose of $600 \mathrm{mg}$ rifampicin, which can potently inhibit the hepatic OATPs, but not CYP3A4, or an intravenous dose of $200 \mathrm{mg}$ itraconazole, which can inhibit hepatic CYP3A4, but not OATPs, was coadministered with a cocktail dose of the three drugs and investigated the changes in their plasma area under the drug concentration-time curves (AUCs). The plasma $A U C$ of midazolam was significantly increased by the coadministration of itraconazole, but not rifampicin (Fig. 4(c)), while that of pravastatin was increased by rifampicin, but not itraconazole (Fig. 4(b)). These results confirmed the selective inhibitory effects of rifampicin and itraconazole on the functions of OATPs and CYP3A4 in humans, respectively, as expected. The plasma $A U C$ of atorvastatin was greatly increased by rifampicin coadministration, but it was not changed by itraconazole (Fig. 4(a)). On the other hand, the plasma concentration of 1-hydroxyatorvastatin, which is one of the major metabolites of atorvastatin produced by CYP3A4, was largely decreased by the coadministration of itraconazole (Fig. 4(d)), which confirmed that CYP3A4-mediated atorvastatin metabolism was inhibited by itraconazole. Therefore, this clinical study clearly indicated that hepatic clearance of atorvastatin was mainly dominated by the hepatic uptake process mediated by OATPs, but not metabolism by CYP3A4 in humans. This study design can also be generally applied to clarify the rate-determining step of the overall hepatic uptake process of OATP substrates in vivo.

\section{CLINICAL IMPORTANCE OF OATP-MEDIATED DRUG-DRUG INTERACTIONS}

OATP-mediated drug-drug interactions (DDIs) in the liver have been rapidly recognized by the discovery of the molecular mechanism of DDI involving cerivastatin. In the United States, 51 patients taking cerivastatin died and in some cases, gemfibrozil was coadministered with cerivastatin. This lethal DDI resulted in the withdrawal of cerivastatin from the market. Recent retrospective analyses also indicated that gemfibrozil coadministration could be a risk factor that causes muscle toxicity induced by cerivastatin. ${ }^{22)}$ Actually, previous clinical reports indicated that the plasma $A U C$ of cerivastatin was increased several-fold in the coadministration of gemfibrozil and cyclosporine A. ${ }^{23)}$ Since cerivastatin is eliminated from the body by CYP2C8- and CYP3A4-mediated metabolism, it is believed that these drugs should inhibit these CYP enzymes at that time. However, Shitara et al. have demonstrated that a clinically-relevant protein unbound concentration of cyclosporine A could not inhibit CYP-mediated metabolism and that inhibition of OATP-mediated hepatic uptake of cerivastatin by cyclosporine $\mathrm{A}$ is a plausible major mechanism of this DDI. ${ }^{24)}$ They also analyzed the mechanism of DDI between cerivastatin and gemfibrozil and concluded that inhibition of both CYP2C8 and OATP1B1 by gemfibrozil glucuronide is a major cause of this DDI. ${ }^{25)}$ The inhibition mode of CYP2C8 by gemfibrozil glucuronide was subsequently found to be mechanismbased inhibition. ${ }^{26)}$ Currently, many examples of DDIs mediated by hepatic OATP transporters have been reported and 


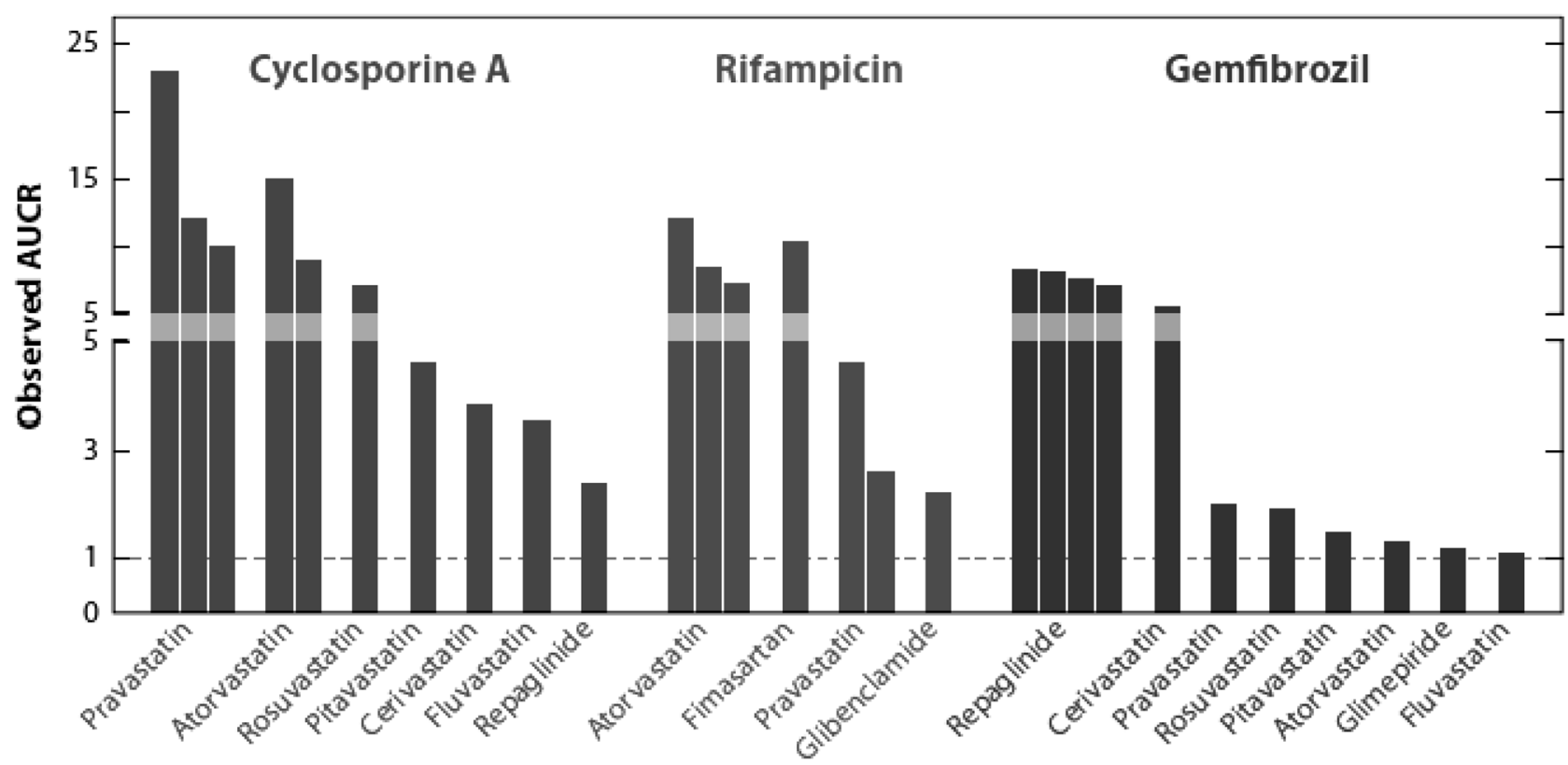

Fig. 5. Plasma AUC Increases of OATP Substrate Drugs in Co-administration with Cyclosporine A, Rifampicin and Gemfibrozil, Typical OATP Inhibitors in Previous Reports

Please note that after administration of gemfibrozil, gemfibrozil glucuronide produced in the liver involves not only the inhibition of OATP1B1-mediated hepatic uptake, but also the mechanism-based inhibition of CYP2C8-mediated metabolism. This graph is cited from ref. 27.

the plasma $A U C$ s of substrate drugs were sometimes greatly increased more than 5-10 fold ${ }^{27)}$ (Fig. 5), which led the regulatory agencies to add OATP1B1 and OATP1B3 as important target sites of DDIs in new (draft) guideline/guidance issued by the US FDA, EMA, and Japanese Ministry of Health, Labour, and Welfare (MHLW). ${ }^{28-30)}$ When estimating the risk of DDIs, if an inhibitor competitively inhibits the OATP1B1mediated transport of a substrate drug and concentration of a substrate drug is far below the Michaelis constant ( $K_{\mathrm{m}}$ value) for OATP1B1, the change of the intrinsic uptake activity is described as shown below.

$$
C L_{\text {int }}(+I)=\frac{C L_{\text {int }}(-I)}{1+\frac{I_{\mathrm{u}}}{K_{\mathrm{i}}}},
$$

where $C L_{\text {int }}(+I), C L_{\text {int }}(-I), I_{\mathrm{u}}$ and $K_{\mathrm{i}}$ represent the intrinsic uptake clearance in the presence of inhibitor, intrinsic uptake clearance in the absence of inhibitor, protein unbound blood concentration of inhibitor, and inhibition constant for OATP1B1, respectively. Because the $1+\left(I_{\mathrm{u}} / K_{\mathrm{i}}\right)$ value is critical for determining the DDI risk, it is often called as the " $R$ value." Since OATP1B1 and OATP1B3 are located on the basal side of hepatocytes, assuming the well-stirred model, the unbound concentration of inhibitors at the inlet to the liver should be considered as $I_{\mathrm{u}}$, though it is impossible to directly measure it. At the early stage of drug development, pharmaceutical researchers want to be able to detect, with a high degree of sensitivity, the DDI risks from a few experimental data, and it is important to avoid a false-negative prediction (i.e., though the prediction result is negative, clinical DDI truly occurs). For such a purpose, a "static model" approach is usually used because the inhibitor concentration is assumed to be constantly maintained in this model and we do not need to consider the real-time change of inhibitor concentration. Moreover, by considering the theoretically-maximum unbound concentration of inhibitors at the target site in the static model, the maximum risk of DDIs can be estimated by Eq. 10 since the inhibitor concentration should be lower at any time in the real situation. The inhibitor at the inlet to the liver is derived not only from that in the blood circulation, but also from that absorbed from the intestine. Thus, inhibitor concentration at the inlet to the liver may be larger than its maximum blood concentration. Ito et al. have proposed the following equation to calculate the theoretically maximum protein unbound inhibitor concentration at the inlet to the liver $\left[I_{\mathrm{u}, \text { in,max }}\right] .{ }^{31)}$

$$
I_{\mathrm{u}, \text { in }, \text { max }}=f_{\mathrm{u}} \times\left(I_{\max }+\frac{k_{\mathrm{a}} \cdot F_{\mathrm{a}} F_{\mathrm{g}} \cdot D}{Q_{\mathrm{h}}}\right),
$$

where $f_{\mathrm{u}}, I_{\max }, k_{\mathrm{a}}, F_{\mathrm{a}} F_{\mathrm{g}}, D$ and $Q_{\mathrm{h}}$ represent the unbound fraction in blood, maximum blood concentration, absorption rate constant, intestinal bioavailability and dose of inhibitor drug, and hepatic blood flow rate, respectively. Using this equation, Ito et al. succeeded in the accurate prediction of CYP-mediated DDI risks while minimizing the false-negative predictions and maximizing the true-positive predictions by the use of $I_{\mathrm{u}, \mathrm{in}, \max }$ value compared with the use of unbound concentration of inhibitor in blood $\left(I_{\mathrm{u}, \max }\right)$ and total concentration of inhibitor in blood $\left(I_{\max }\right){ }^{32)}$ Following this concept, we previously tried to predict the OATP1B1- and OATP1B3mediated DDI potentials of several OATP inhibitor drugs in in vitro inhibition assays with gene expression systems. ${ }^{11,33)}$ As a result, by searching for drugs with estimated $R$ values at a therapeutic dose of more than 2 among the drugs tested, clinically-relevant doses of cyclosporine A and rifampicin can inhibit both OATP1B1 and OATP1B3, while clarithromycin, rifamycin SV and indinavir can inhibit OATP1B1 at their clinical doses. For most of these drugs, clinical DDIs have also been reported, suggesting the validity of static model analyses with the $I_{\mathrm{u}, \text { in, } \max }$ value.

Yoshida et al. investigated the predictability of the risk of DDIs involving OATP transporters using a static model. ${ }^{34)}$ They systematically collected the 58 DDI studies involving 
12 substrates of OATP transporters from the literature. The $R$ value for each DDI case was evaluated and the predicted $A U C$ increases were compared with the observed ones. To avoid false-negative predictions, the impact of three assumptions on the predictability of DDI risks was evaluated. In the first assumption, the maximum inhibitory effects of inhibitor drugs on CYP3A and efflux transporters (P-gp, MRP2, BCRP) were considered if they were judged to be inhibited by drugs in the small intestine based on the drug interaction number (DIN) proposed by Tachibana et al. ${ }^{35)}$ They defined DIN as the dose divided by the $K_{\mathrm{i}}$ value and used threshold values of $2.8 \mathrm{~L}$ for CYP3A and $10.8 \mathrm{~L}$ for P-gp, above which inhibition of CYP3A or P-gp may occur in the human intestine. Thus, if the DINs of inhibitor drugs exceeded the threshold values, $F_{\mathrm{a}} F_{\mathrm{g}}$ values were assumed to become 1 in coadministration with inhibitor drugs. By adding this assumption, the number of false-negative predictions was decreased slightly $(19 \rightarrow 16$ studies). In the second assumption, to verify whether $I_{\mathrm{u}, \text { in, } \max }$ is the best choice to calculate $R$ values for the accurate prediction of DDI risks with minimizing false-negative prediction, which is the same as the prediction of CYP-based DDIs, is verified. Thus, the number of false-negative predictions was compared when $R$ values were calculated with $I_{\mathrm{u}, \text { in, } \max }$ as well as $I_{\mathrm{u}, \max }$ and $I_{\max }$. Expectedly, the use of $I_{\mathrm{u}, \text { in, } \max }$ minimized the number of false-negative predictions. When $I_{\max }$ was used, the number of false-positive predictions greatly increased because several clinically relevant OATP inhibitors showed a very low protein-unbound fraction and the discrepancy between the total and unbound concentrations of such inhibitors was large. In the third assumption, the maximum inhibitory effects of biliary efflux transporters and/or metabolic enzymes as well as uptake transporters on the decreased hepatic intrinsic clearance were considered. As mentioned above, if the $\beta$ value in Eq. 4 is close to 1 , the overall intrinsic hepatic clearance is described as Eq. 5 and only the inhibition of uptake transporter should be considered. But if the $\beta$ value is far below 1, the overall intrinsic hepatic clearance is described as Eq. 6 and the intrinsic clearance of not only hepatic uptake but also biliary excretion, metabolism and backflux to blood should be considered. Thus, to minimize the false-negative predictions, the maximum inhibitory effects on multiple processes when substrate drugs are recognized by uptake transporters, efflux transporters, and/or metabolic enzymes should be considered by estimating the product of the $R$ values for uptake and excretion and/or metabolism with the $I_{\mathrm{u}, \mathrm{in}, \max }$ value. As a result, the number of false-negative predictions can be minimized when the product of $R$ values was used for the DDI prediction rather than just the $R$ value for uptake $(16 \rightarrow 11$ studies). In particular, DDI cases between fluconazole and CYP2C9 substrates (glimepiride, nateglinide, irbesartan) are predicted correctly when we consider the maximum inhibitory effects of both uptake and metabolism. This is reasonable because the clinical dose of fluconazole does not cause the inhibition of OATP-mediated uptake, but inhibits CYP2C9-mediated metabolism. However, when the product of the $R$ values for all the processes was considered, the number of false-positive predictions was increased and the overall prediction accuracy was the highest when only the $R$ value for uptake was considered $(76 \%$ and $90 \%$ for predictions within two- to threefold of the observed $A U C R$ values, respectively).

In the regulatory guidance/guideline, static model analy- ses are used to judge the need for clinical DDI studies in the process of new drug development. ${ }^{28-30)}$ In the U.S. FDA draft guidance on DDIs, when an investigational drug is suspected to be an inhibitor of hepatic OATPs, if the $I_{\max } / K_{\mathrm{i}}$ value is more than 0.1 and the $R$ value calculated with $I_{\mathrm{u}, \text { in, } \max }$ is more than 1.25 , in vivo clinical DDI studies with OATP substrate drugs are recommended. ${ }^{28)}$ In the Japanese MHLW draft guideline, the threshold for the $R$ value calculated with $I_{\mathrm{u}, \mathrm{in}, \max }$ is $1.25,{ }^{30)}$ while in the EMA guideline, the threshold is $1.04,{ }^{29)}$ which is more strict than that in the FDA and MHLW draft guidance/guidelines.

Determination of the $K_{\mathrm{i}}$ value is also a critical factor for the accurate prediction of DDI risks. In the routine inhibition assay in the process of drug development, $K_{\mathrm{i}}$ values of multiple drugs are determined at one time by using a single prototypical substrate of OATPs such as estradiol-17 $\beta$-glucuronide $\left(\mathrm{E}_{2} 17 \beta \mathrm{G}\right)$ and $\mathrm{E}$-sul. However, previous reports indicated the substrate dependence of the $K_{\mathrm{i}}$ value of the same inhibitor. Noe et al. demonstrated that $200 \mu \mathrm{M}$ gemfibrozil significantly inhibited the OATP1B1-mediated uptake of taurocholate and statins, but not that of E-sul and troglitazone sulfate. ${ }^{36)}$ Soars et al. compared the $\mathrm{IC}_{50}$ values of 8 drugs for OATP1B1mediated uptake of three prototypical substrates (pitavastatin, $\mathrm{E}_{2} 17 \beta \mathrm{G}$ and $\mathrm{E}$-sul). ${ }^{37)}$ The overall trend in the rank order of $\mathrm{IC}_{50}$ values was $\mathrm{E}_{2} 17 \beta \mathrm{G} \leqq$ pitavastatin $<\mathrm{E}$-sul. Izumi et al. have also recently showed the inhibitory effects of 14 compounds on the OATP1B1-mediated uptake of three kinds of prototypical substrates, $\mathrm{E}_{2} 17 \beta \mathrm{G}$, E-sul and bromosulfophthalein (BSP). ${ }^{38)}$ As a result, although the $K_{\mathrm{i}}$ value of the same inhibitor was sometimes estimated to be very different depending on the substrates tested, regardless of the inhibitors tested, the most potent OATP1B1 inhibition was observed when $\mathrm{E}_{2} 17 \beta \mathrm{G}$ was used as a substrate. These results indicated that it is recommended to use the real combination of substrate and inhibitor when predicting the risk of specific DDI cases, while $\mathrm{E}_{2} 17 \beta \mathrm{G}$ may be used for a routine high-throughput inhibition assay to perform more conservative DDI prediction. Following the regular protocol of transporter inhibition assay, a substrate and an inhibitor are co-incubated without any preincubation of an inhibitor. However, time-dependent inhibition of OATP transporters has been reported in in vitro experiments. Shitara et al. have shown that in vivo hepatic uptake of BSP determined by the liver uptake index method was significantly decreased $3 \mathrm{~d}$ after administration of cyclosporine $\mathrm{A}$ in rats, though cyclosporine A had already been almost eliminated from the blood circulation. ${ }^{39)}$ They also observed the uptake of BSP in rat hepatocytes was also continuously decreased after preincubation with cyclosporine $\mathrm{A}$ and its subsequent its removal from the medium. Amundsen et al. also demonstrated that the apparent $K_{\mathrm{i}}$ value of cyclosporine A for the uptake of atorvastatin after 1-h preincubation with cyclosporine A was $1 / 22$ of that in its coincubation. ${ }^{40)}$ Thus, it should be noted that the $K_{\mathrm{i}}$ value obtained from the conventional assay may be overestimated, which leads to the underestimation of DDI risks.

\section{GENETIC POLYMORPHISMS OF OATP1B1 AND OATP1B3 AND THEIR CLINICAL RELEVANCE}

Many kinds of genetic variations of SLCO1B1, which encodes OATP1B1, have been reported. Among them, the effects 


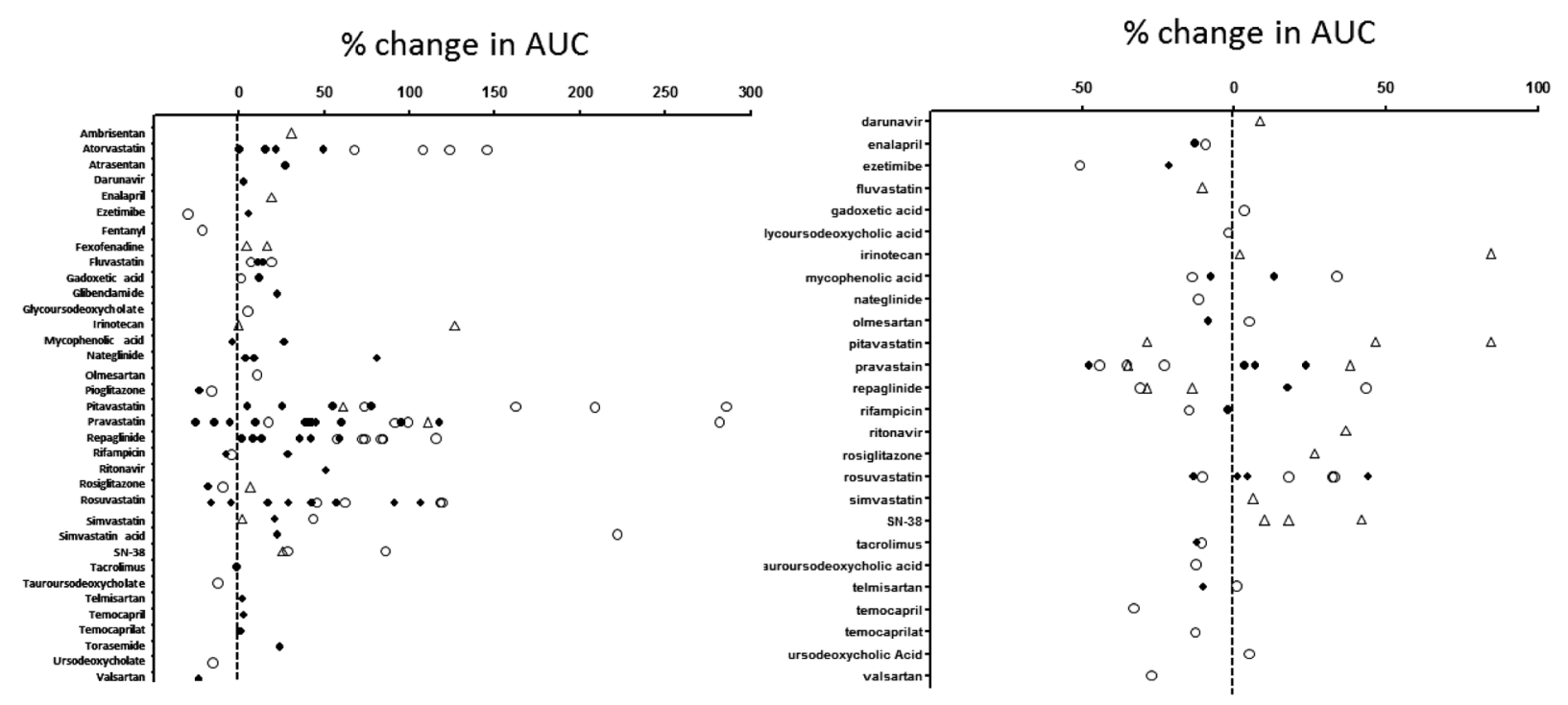

Fig. 6. Influence of $S L C O 1 B 1$ c.521T $>\mathrm{C}$ (a) or c.388A $>\mathrm{G}$ (b) on the Change of Plasma $A U C$ s of Various Drugs Previously Tested in Humans

This graph shows the percent change in plasma $A U C$ in subjects with specified genotypes $\left(A U C_{\mathrm{m}}\right)$ compared with that in subjects with wild type allele $\left(A U C_{\mathrm{w}}\right)$ [\% change in $\left.A U C=\left(A U C_{\mathrm{m}}-A U C_{\mathrm{w}}\right) / A U C_{\mathrm{w}} \times 100\right]$. Each plot represents a single curated record cited from the Drug Interaction Database (DIDB) created by University of Washington, School of Pharmacy. Open circle: homozygotes of mutated alleles (mut/mut) vs. homozygotes of wild type alleles (wt/wt). Closed circle: wt/mut vs. wt/wt. Open triangle: (wt/wt and wt/mut) vs. mut/mut or wt/wt $v s$. (wt/mut and mut/mut).

of two major genetic polymorphisms in SLCO1B1, c.388A $>\mathrm{G}$ (p.130N $>$ D) and c.521T $>$ C (p.174V $>$ A), on the pharmacokinetics and subsequent pharmacodynamics/toxicity have been extensively been studied. ${ }^{41,42)}$ Nishizato et al. have found that c.521T $>\mathrm{C}$ mutation is tightly linked to c.388A $>\mathrm{G}$ mutation in Japanese with a high frequency and these mutations form a haplotype named $S L C O 1 B 1 * 15 .^{43)}$ They conducted a clinical study in which the plasma concentration of pravastatin in subjects with $* 15$ allele was significantly higher than that in subjects with $* 1 b(c .388 \mathrm{~A}>\mathrm{G})$ allele, which is the first demonstration of a relationship between genetic polymorphisms of SLCO1B1 and the pharmacokinetics of substrate drugs. Afterwards, Iwai et al. showed that OATP1B1*15 mutated protein showed significantly lower $V_{\max }$ values of the uptake of substrates normalized by protein expression level compared with wild type allele (OATP1B1*1a). ${ }^{44)}$ At present, it is common knowledge that c.521T $>\mathrm{C}$ decreased the transport function of OATP1B1, although several researchers have reported different reasons for the decreased function of OATP1B1 by this mutation. Figure 6(a) summarizes the impact of c.521T $>C$ in $S L C O 1 B 1$ on the plasma $A U C$ s of various drugs based on the previous literature information. Among the drugs tested, the increase in the plasma $A U C$ was relatively high for several statins and glinides. On the other hand, regarding c.388A $>\mathrm{G}$ mutation, Mwinyi et al. have shown a decrease in the plasma concentration of pravastatin in subjects with c.388A $>\mathrm{G}$ allele compared with its non-carriers. ${ }^{45}$ We have also previously performed a crossover type of clinical study to clarify whether or not OATP1B1*1b allele affects the pharmacokinetics of three substrate drugs (valsartan, pravastatin, temocapril). ${ }^{46}$ ) The plasma concentration of pravastatin was significantly lower in subjects with *1b allele compared with *1a, while those of valsartan and temocapril were slightly lower in subjects with $* 1 b$, although the differences did not reach statisti- cal significance. Interestingly, the plasma $A U C$ s of valsartan and temocapril in the individual subjects were well correlated with those of pravastatin, suggesting that these three drugs share the same clearance mechanism, OATP1B1-mediated hepatic uptake. However, increased function of OATP1B1 by c. $388 \mathrm{~A}>\mathrm{G}$ was not reproduced in the in vitro experiments. ${ }^{44}$ ) A recent report suggested that the protein expression level of OATP1B1*1b was larger in human hepatocytes compared with OATP1B1*1a protein, which may increase the $V_{\max }$ value of hepatic uptake. ${ }^{47)}$ Figure 6(b) summarizes the impact of c. $388 \mathrm{~A}>\mathrm{G}$ in $S L C O 1 B 1$ on the plasma $A U C$ s of various drugs based on information in the literature. Although inter-test differences in the change of plasma $A U C$ were very large, especially in homozygotes of $S L C O 1 B 1$ c.388A $>$ G allele, the plasma $A U C$ s of pravastatin and some other OATP1B1 substrate drugs tended to be lower than that in subjects with the wild type allele. Clinical studies have been conducted to clarify the impact of genetic polymorphisms of SLCO1B1 on the pharmacological/toxicological effects of substrate drugs (Table 2). Since the pharmacological target of statins is HMG-CoA reductase in the liver, researchers initially believed that a change in the hepatic uptake clearance of statins leads to the altered cholesterol lowering effect. Though some reports have found a decrease in cholesterol synthesis in subjects with $S L C O 1 B 1^{*} 15$ or $* 17(* 15+$ c. $-11187 \mathrm{G}>\mathrm{A})$, most of the previous clinical reports could not clearly show any significant difference in the pharmacological effect (lowering plasma low density lipoprotein (LDL)-cholesterol level) of statins. ${ }^{48)}$ Watanabe et al. attempted to explain this from the viewpoint of pharmacokinetic theory. ${ }^{49)}$ They constructed a physiologically-based pharmacokinetic (PBPK) model of pravastatin in humans and simulated the time profile of plasma and hepatic concentrations of pravastatin in a unique situation. When the hepatic uptake intrinsic clearance was decreased, the simulation results indicat- 
Table 2. Effects of Genetic Polymorphisms of SLCOIB1 on the Pharmacological Effects of Substrate Drugs

(a) Statins: LDL cholesterol-lowering effect

\begin{tabular}{|c|c|c|c|c|c|}
\hline & $\begin{array}{l}\text { Genotype } \\
\text { (control) }\end{array}$ & $\begin{array}{l}\text { Genotype } \\
\text { (case) }\end{array}$ & $\begin{array}{l}\text { Number of subjects } \\
\text { (case) }\end{array}$ & $\begin{array}{c}\text { LDL cholesterol } \\
\text { (change from baseline) } \% \Delta\end{array}$ & References \\
\hline \multirow[t]{4}{*}{ Atorvastatin } & $521 \mathrm{TT}$ & $521 \mathrm{TC}$ & 49 & -4.68 & \multirow{2}{*}{ 75) } \\
\hline & $521 \mathrm{TT}$ & $521 \mathrm{CC}$ & 7 & -3.6 & \\
\hline & 388AA & 388AG & 28 & -369.57 & \multirow{2}{*}{ 76) } \\
\hline & 388AA & $388 \mathrm{GG}$ & 13 & -352.17 & \\
\hline \multirow[t]{6}{*}{ Pravastatin } & $* 1 \mathrm{a} / * 1 \mathrm{a}$ & $\begin{array}{c}* 1 \mathrm{a} / * 15 \text { or } \\
* 1 \mathrm{a} / * 17 \text { or } \\
* 17 / * 17\end{array}$ & 8 & 34.41 & 77) \\
\hline & $521 \mathrm{TT}$ & $521 \mathrm{TC}$ & 164 & 0 & \multirow{2}{*}{ 78) } \\
\hline & $521 \mathrm{TT}$ & $521 \mathrm{CC}$ & 13 & 20.27 & \\
\hline & $-11187 \mathrm{GG}$ & $-11187 \mathrm{GA}$ & 2 & -19.81 & \multirow{3}{*}{ 79) } \\
\hline & $521 \mathrm{TT}$ & $521 \mathrm{TC}$ & 6 & -15.42 & \\
\hline & $521 \mathrm{TT}$ & $521 \mathrm{TC}$ & 3 & $77.01^{\#}$ & \\
\hline \multirow[t]{4}{*}{ Rosuvastatin } & 388AA & 388AG & 91 & -7.71 & \multirow{4}{*}{ 80) } \\
\hline & 388AA & $388 \mathrm{GG}$ & 147 & -9.17 & \\
\hline & $521 \mathrm{TT}$ & $521 \mathrm{TC}$ & 62 & -1.35 & \\
\hline & $521 \mathrm{TT}$ & $521 \mathrm{CC}$ & 5 & -9.28 & \\
\hline \multirow[t]{3}{*}{ Simvastatin } & $521 \mathrm{TT}$ & $521 \mathrm{TC}$ & 46 & 6.25 & \multirow{3}{*}{ 75) } \\
\hline & $521 \mathrm{TT}$ & $521 \mathrm{CC}$ & 5 & 13.24 & \\
\hline & $* 1 \mathrm{a} / * 1 \mathrm{a}$ & $* 15 / * 15$ & 4 & -4.04 & \\
\hline \multicolumn{6}{|c|}{ (b) Glinides: Decrease in the blood glucose level } \\
\hline & $\begin{array}{l}\text { Genotype } \\
\text { (control) }\end{array}$ & $\begin{array}{l}\text { Genotype } \\
\text { (case) }\end{array}$ & $\begin{array}{l}\text { Number of subjects } \\
\text { (case) }\end{array}$ & $\begin{array}{l}\text { Blood glucose } A U C \text { (or level) } \\
\text { (change from baseline) } \% \Delta\end{array}$ & References \\
\hline \multirow[t]{4}{*}{ Nateglinide } & $* 1 \mathrm{a} / * 1 \mathrm{a}$ & $* 1 \mathrm{~b} / * 1 \mathrm{~b}$ & 8 & -45 & 81) \\
\hline & $521 \mathrm{TT}$ & $521 \mathrm{TC}$ & 12 & -80 & \multirow{2}{*}{ 53) } \\
\hline & $521 \mathrm{TT}$ & $521 \mathrm{CC}$ & 4 & -50 & \\
\hline & $\begin{array}{c}521 \mathrm{TT} \\
(\mathrm{CYP} 2 \mathrm{C} 9 * 1 / * 1)\end{array}$ & $\begin{array}{l}521 \mathrm{TC} \text { or } 521 \mathrm{CC} \\
(\mathrm{CYP} 2 \mathrm{C} 9 * 1 / * 1)\end{array}$ & 13 & 30 & 82) \\
\hline \multirow[t]{9}{*}{ Repaglinide } & $* 1 \mathrm{a} / * 1 \mathrm{a}$ & $* 1 \mathrm{~b} / * 1 \mathrm{~b}$ & 8 & 21.05 & 81) \\
\hline & $521 \mathrm{TT}$ & $521 \mathrm{TC}$ & 16 & $33.33^{1)}$ & \multirow{2}{*}{ 54) } \\
\hline & $521 \mathrm{TT}$ & $521 \mathrm{CC}$ & 4 & $-100^{1)}$ & \\
\hline & $\begin{array}{c}521 \mathrm{TT} \\
(\mathrm{CYP} 2 \mathrm{C} 8 * 1 / * 1)\end{array}$ & $\begin{array}{c}521 \mathrm{TC} \\
(\mathrm{CYP} 2 \mathrm{C} 8 * 1 / * 1)\end{array}$ & 3 & $-25^{1)}$ & 55) \\
\hline & $-11187 \mathrm{GG}$ & $-11187 \mathrm{GA}$ & 8 & -200 & 54) \\
\hline & $521 \mathrm{TT}$ & $521 \mathrm{TC}$ & 12 & -13.16 & \multirow[t]{2}{*}{ 53) } \\
\hline & $521 \mathrm{TT}$ & $521 \mathrm{CC}$ & 4 & -34.21 & \\
\hline & $* 1 \mathrm{a} / * 1 \mathrm{a}$ or $* 1 \mathrm{a} / * 1 \mathrm{~b}$ & $* 1 \mathrm{~b} / * 1 \mathrm{~b}$ & 4 & 4.76 & \multirow[t]{2}{*}{ 83) } \\
\hline & $* 1 \mathrm{a} / * 1 \mathrm{a}$ or $* 1 \mathrm{a} / * 1 \mathrm{~b}$ & $* 1 \mathrm{a} / * 5$ or $* 1 \mathrm{a} / * 15$ & 7 & 9.52 & \\
\hline
\end{tabular}

(c) Raloxifene: Prevention of osteoporosis

\begin{tabular}{lcccc}
\hline & $\begin{array}{c}\text { Genotype } \\
\text { (control) }\end{array}$ & $\begin{array}{c}\text { Genotype } \\
\text { (case) }\end{array}$ & $\begin{array}{c}\text { Number of subjects } \\
\text { (case) }\end{array}$ & $\begin{array}{c}\text { Femoral neck bone mineral density } \\
\text { (or quantitative ultrasound index) } \\
\text { (change from baseline) } \% \Delta\end{array}$ \\
\hline Raloxifene & $388 \mathrm{AA}$ & $388 \mathrm{AG}$ & 28 & $409.09^{\#}$ \\
& $521 \mathrm{TT}$ & $521 \mathrm{TC}$ & 18 & $-164^{2)}$ \\
& $388 \mathrm{AA}$ & $388 \mathrm{GG}$ & 11 & 45.45 \\
\hline
\end{tabular}

(d) Torasemide: Diuretic effect

\begin{tabular}{ccccc}
\hline & $\begin{array}{c}\text { Genotype } \\
\text { (control) }\end{array}$ & $\begin{array}{c}\text { Genotype } \\
\text { (case) }\end{array}$ & $\begin{array}{c}\text { Number of subjects } \\
\text { (case) }\end{array}$ & Sodium urine excretion\% $\Delta$ \\
\hline Torasemide & $388 \mathrm{AA}$ & $388 \mathrm{GG}$ & 7 & $-18.6^{\#}$ \\
& $388 \mathrm{AA}$ & $388 \mathrm{AG}$ & 29 & -6.98 \\
\hline
\end{tabular}

\# represents the statistically significant difference mentioned in each report. 1) Blood glucose level at the specified time. 2) Quantitative Ultrasound Index. *1a: $388 \mathrm{~A}, 521 \mathrm{~T}$, *1b: 388G, 521T, *5: 388A, 521C, *15: 388G, 521C, *17: -11187A, 388G, 521C

ed that the plasma concentration of pravastatin was greatly increased, whereas its intrahepatic concentration was not greatly altered. This can be intuitively understood by the in- creased plasma concentration and decreased hepatic uptake clearance, which results in little change in the hepatic concentration because the hepatic uptake rate was determined by 
multiplying the plasma concentration by the hepatic uptake clearance. Thus, it is reasonable that decreased function of OATP1B1 by c.521T $>$ C mutation does not affect the pharmacological effect of statins. On the other hand, as indicated above, decreased hepatic uptake causes an increase in the plasma concentration of statins. One of the severe side effects of statins is muscle toxicity such as myopathy and rhabdomyolysis. Since the toxicological target of statins is striated muscle, its exposure to statins is thought to be determined by their plasma concentrations. Interestingly, as a sub analysis of the SEARCH (Study of the Effectiveness of Additional Reductions in Cholesterol and Homocysteine) study, the GWAS (Genome-wide association study) approach to dig out the genetic background which increases the risk of myopathy induced by simvastatin revealed that a tag SNP, which is tightly linked to SLCO1B1 c.521T >C, is the only mutation to determine the risk of myopathy expression. ${ }^{50)}$ A replication study also suggested that the odds ratio of the risk of myopathy expression in patients taking simvastatin within one year was 4.5 and 16.9 in heterozygotes and homozygotes of c.521T $>C$ allele, respectively. Similar tendencies were also reproduced in other large clinical studies. The STRENGTH (Statin Response Examined by Genetic Haplotype Markers) study reported a significant increase in mild myotoxicity in subjects with c.521T $>\mathrm{C}$ in SLCO1B1 taking atorvastatin, simvastatin or pravastatin. ${ }^{51)}$ The Go-DARTS (Genetics of Diabetes Audit and Research) study also showed a higher frequency of the discontinuation of statin therapy in subjects with c.521T $>C$, and a lower frequency in subjects with c.388A $>\mathrm{G}^{52)}$ The impact of genetic polymorphisms of SLCOIB1 on the pharmacological/toxicological effects of substrate drugs is not limited to statins. The plasma concentration of the anti-diabetes drug repaglinide was slightly higher (Fig. 6(a)) and subsequently the blood glucose level was lower in subjects with c.521T $>\mathrm{C}$ or c. $-11187 \mathrm{G}>\mathrm{A}$ in $S L C O 1 B 1$, whereas the plasma concentration was lower and the blood glucose level was higher in subjects with $* 1 \mathrm{~b}$ allele. ${ }^{53-55)}$ Although the reason for the decreased function of OATP1B1 by c. $-11187 \mathrm{G}>\mathrm{A}$ is unknown, it is frequently linked to c.521T $>\mathrm{C}$ and c.521T $>\mathrm{C}$ may be a direct cause of functional change of OATP1B1. SLCO1B1 c.521T $>$ C also increased the glucose lowering effect by nateglinide. ${ }^{53)}$ As for the relationship between the pharmacological effects of other OATP substrate drugs and genetic polymorphisms of $S L C O 1 B 1$, the diuretic effect of torasemide was reported to be significantly decreased by c. $388 \mathrm{~A}>\mathrm{G}^{56)}$ and the pharmacological effect of raloxifene, an oral selective estrogen receptor modulator for the prevention of osteoporosis in postmenopausal women, was superior as judged from the change in bone turnover markers, and the raloxifene concentration was also higher in subjects with c. $388 \mathrm{~A}>\mathrm{G},{ }^{57)}$ although this tendency is inconsistent with other cases demonstrating enhanced hepatic uptake by c.388A $>\mathrm{G}$. Various reports have described the relationship between the genetic polymorphisms of SLCO1B1 and toxicological effects of OATP substrate drugs other than statins. Irinotecan, an anticancer drug, is a prodrug, which is converted to its active metabolite, SN-38, by carboxyl esterase. A previous report indicated that $\mathrm{SN}-38$ is a substrate of OATP1B1 and its transport was significantly lower in OATP1B1*15-expressing cells compared with OATP1B1*1aexpressing cells. ${ }^{58)}$ In cancer patients treated with irinotecan, the plasma concentration of SN-38 was higher and the risk of severe neutropenia was increased by c.521T $>C$, while the risk of severe diarrhea (intestinal toxicity) was increased by c. $388 \mathrm{~A}>\mathrm{G} .{ }^{59)}$ This was explained by the increased exposure of $\mathrm{SN}-38$ to the precursor of blood cells by c.521T $>\mathrm{C}$ and its increased exposure to the intestinal tract due to the increased biliary excretion of $\mathrm{SN}-38$ by c. $388 \mathrm{~A}>\mathrm{G}$. In the case of methotrexate, an intronic mutation in SLCO1B1, rs11045879C $>$ T, increased the clearance of methotrexate and increased the risk of severe intestinal toxicity 16.4-fold, while c.521T $>\mathrm{C}$ decreased the methotrexate clearance and the risk of intestinal toxicity. ${ }^{60)}$

Shitara et al. tried to simultaneously estimate the contribution of OATP1B1 to the overall hepatic uptake of OATP substrate drugs and decreased function of OATP1B1 by c.521T $>\mathrm{C}$ mutation in humans based on previous clinical pharmacogenetic studies. ${ }^{61)}$ In this approach, since hepatic intrinsic clearance is proportional to the intrinsic uptake clearance following the pharmacokinetic theory, the ratio of hepatic intrinsic clearance of each substrate drug in subjects with 521CC to that in subjects with 521TT was first estimated based on the reported $A U C$ increase of the drug by c.521T $>\mathrm{C}$ mutation. This ratio can be expressed as shown below.

$$
\frac{C L_{\text {int, all (521CC) }}}{C L_{\text {int, all (521TT) }}}=1-\alpha \times\left(1-R P S_{\text {inf }(521 \mathrm{~T}>\mathrm{C})}\right),
$$

where $\alpha$ and $R P S_{\text {inf(521T>C) }}$ represent the contribution of OATP1B1 to the total hepatic uptake in subjects carrying SLCO1B1 521TT and the ratio of transport activity of mutated OATP1B1 (521C) to that of wild type OATP1B1 (521T), respectively. The same concept can be applied to the calculation of the ratio of hepatic intrinsic clearance of drugs in subjects with 521TC to that in subjects with 521TT as shown below.

$$
\frac{C L_{\text {int, all (521TC) }}}{C L_{\text {int, all (521TT) }}}=1-\frac{\alpha \times\left(1-R P S_{\text {inf }(521 \mathrm{~T}>\mathrm{C})}\right)}{2}
$$

The contribution of OATP1B1 to the hepatic uptake of pitavastatin, rosuvastatin and olmesartan has already been estimated by in vitro experiments, and thus by regarding in vitro estimates as $\alpha, R P S_{\inf (521 \mathrm{~T}>\mathrm{C})}$ was calculated by the results of clinical pharmacogenetic studies. Then, unknown $\alpha$ values of other OATP substrates were estimated by the use of the estimated $R P S_{\inf (521 \mathrm{~T}>\mathrm{C})}$. As a result, $R P S_{\mathrm{inf}(521 \mathrm{~T}>\mathrm{C})}$ was estimated to be 0.347 and the OATP1B1 contribution was estimated to be in the rank order of pravastatin, pitavastatin, rosuvastatin $>$ atorvastatin, fexofenadine, torasemide, olmesartan $>$ fluvastatin. Though we neglected the substratedependence of the decreased transport function of OATP substrates due to the fixed $R P S_{\text {inf(521T }>C)}$ in our calculations and the amount of in vitro and in vivo data is still very limited, the concept of this approach is generally useful to quantitatively estimate the impact of genetic polymorphisms of transporters on the pharmacokinetics of different substrate drugs from the clinical data.

As for OATP1B3, two mutations, c.334T $>\mathrm{G}$ (p.112S $>\mathrm{A})$ and c.699G $>$ A (p.233M $>$ I), are frequently observed in all ethnicities. A previous report indicated that these two mutations did not affect the membrane localization and transport activity of substrates in the in vitro study. ${ }^{62)}$ In clinical studies, two contradictory findings have been reported about the effect of these mutations on the pharmacokinetics of micophenolate mofetil ${ }^{63,64)}$ and Chew et al. have suggested 
one haplotype containing c.699G $>$ A decreased the clearance of docetaxel in patients with nasopharyngeal neoplasms. ${ }^{65}$ ) Kiyotani et al. found that rs12762549 in $A B C C 2$ (encoding MRP2) and rs11045585 (1683-5676A $>$ G) in SLCO1B3 are significantly associated with the expression of docetaxel-induced severe neutropenia based on the genetic analyses of human samples from BioBank Japan. ${ }^{66)}$ After that, the plasma $A U C$ of telmisartan, which is a selective substrate for OATP1B3, was slightly larger in heterozygotes of SLCO1B3 $\mathrm{rs} 11045585 \mathrm{~A}>\mathrm{G}$ and was 1.4-fold larger than that in homozygotes of wild-type alleles, though the difference in $A U C$ did not reach statistical significance. ${ }^{67)}$ Considering these findings, Yamada et al. constructed a PK/PD model containing the function of OATP1B3 and MRP2 to explain the change of neutrophil count by the administration of docetaxel and found that clinical data were well reproduced by the decreased function of OATP1B3 and MRP2 to 41 and $32 \%$, respectively. ${ }^{68)}$ Thus, even though SLCO1B3 $\operatorname{rs} 11045585 \mathrm{~A}>\mathrm{G}$ is located in the intronic region and it is difficult to investigate the functional change of OATP1B3 by this mutation in vitro, clinical study with a modeling approach can predict its effect on the transport function quantitatively.

\section{CONCLUSION}

This review briefly mentioned the current knowledge about the clinical impact of hepatic OATP1B1 and OATP1B3 on the pharmacokinetics and subsequent pharmacological/toxicological effects of substrate drugs and its prediction methods. Clinical evidence has indicated that coadministration of OATP inhibitors and genetic polymorphisms in SLCO genes can alter the pharmacokinetics of substrate drugs, but the extent of $A U C$ change largely depends on various pharmacokinetic properties of the drugs such as the contribution of each transporter to the overall hepatic clearance of drugs, the rate-determining process of hepatic intrinsic clearance, and the fraction excreted into urine. To quantitatively predict the pharmacokinetics of drugs in special situations like DDIs, the importance of physiologically-based pharmacokinetic (PBPK) modeling while taking multiple factors discussed above into consideration has been recognized. Interestingly, the simulation results of a PBPK model to explain the CYP3A-mediated DDIs with iburutinib appeared in the package insert of IMBRUVICA ${ }^{\circledR}$ in the United States. ${ }^{69)}$ This suggests that the reliable PBPK model may exempt the real clinical DDI studies.

However, when many factors are incorporated into a PBPK model, the number of model parameters should be very large and some of the parameters cannot easily be set up only from in vitro experimental data. To further optimize the accuracy of a PBPK model, one of the strategies is to increase the in vivo pharmacokinetic data of drugs, such as tissue drug concentration. Recently, to non-invasively perform the real-time measurement of the tissue concentration of drugs, several kinds of positron emission tomography (PET) probes for evaluating OATP function have been created and characterized in rodents and humans. ${ }^{70-73)}$ By using the time profile data for tissue concentration as well as the plasma concentration of drugs to optimize the model parameters, we can further increase the reliability of a PBPK model. Another strategy is to create methods for extracting multiple candidate sets of model parameters which can reproduce a limited number of clinical data. In the conventional approach to optimize multiple parameters in a PBPK model such as the Gauss-Newton method, we must set up the initial value for each parameter and finally obtain a single set of optimized parameters. Moreover, these optimized values sometimes largely depend on their initial values and since the pharmacokinetic data obtained from human study (plasma concentration and urinary excreted amount) are very limited, only a single set of model parameters is not always a real solution to reproduce the clinical pharmacokinetic data. We recently proposed the use of the Cluster-Newton Method to exhaustively obtain the candidate sets of multiple model parameters. ${ }^{74)}$ Among these candidate answers, a plausible set of parameters can be selected by using other clues such as in vitro experimental data.

In conclusion, it is evident that OATP1B1 and OATP1B3 in the liver act as important regulators of pharmacokinetics of various kinds of substrate drugs. Therefore, we pay further attention to the causes of the functional change of OATPs and the universal methods for an accurate prediction of the pharmacokinetics of OATP substrate drugs by the use of a PBPK model from in vitro data as well as limited clinical in vivo data should be needed and verified.

Acknowledgments I would like to thank my former supervisor, Dr. Yuichi Sugiyama (Sugiyama Laboratory, RIKEN Innovation Center, RIKEN) and my current supervisor, Prof. Hiroyuki Kusuhara (Lab. of Molecular Pharmacokinetics, Graduate School of Pharmaceutical Sciences, The University of Tokyo) for their great guidance and suggestions. I also wish to express my sincere thanks to all of my colleagues and collaborators for their kind support of my research. This work was supported in part by Grants-in-Aid for Scientific Research from the Japan Society for the Promotion of Science.

Conflict of Interest The author declares no conflict of interest.

\section{REFERENCES}

1) Hagenbuch B, Stieger B. The SLCO (former SLC21) superfamily of transporters. Mol. Aspects Med., 34, 396-412 (2013).

2) König J, Cui Y, Nies AT, Keppler D. Localization and genomic organization of a new hepatocellular organic anion transporting polypeptide. J. Biol. Chem., 275, 23161-23168 (2000).

3) Chu X, Bleasby K, Evers R. Species differences in drug transporters and implications for translating preclinical findings to humans. Expert Opin. Drug Metab. Toxicol., 9, 237-252 (2013).

4) Maeda K, Sugiyama Y. Excretion systems. Encyclopedia of Drug Metabolism and Interactions. (Lyubimov A, et al. eds.) Vol. 3, Wiley, New York, pp. 1-32 (2012).

5) Briz O, Serrano MA, MacIas RI, Gonzalez-Gallego J, Marin JJ. Role of organic anion-transporting polypeptides, OATP-A, OATP-C and OATP- 8 , in the human placenta-maternal liver tandem excretory pathway for foetal bilirubin. Biochem. J., 371, 897-905 (2003).

6) Cui Y, Konig J, Leier I, Buchholz U, Keppler D. Hepatic uptake of bilirubin and its conjugates by the human organic anion transporter SLC21A6. J. Biol. Chem., 276, 9626-9630 (2001).

7) van de Steeg E, Stranecky V, Hartmannova H, Noskova L, Hrebicek M, Wagenaar E, van Esch A, de Waart DR, Oude Elferink RP, Kenworthy KE, Sticova E, al-Edreesi M, Knisely AS, Kmoch S, Jirsa M, Schinkel AH. Complete OATP1B1 and OATP1B3 deficiency causes human Rotor syndrome by interrupting conjugated bilirubin reuptake into the liver. J. Clin. Invest., 122, 519-528 (2012). 
8) Maeda K, Sugiyama Y. In vitro-in vivo Scale-up of Drug Transport Activities. Drug Transporters. (You G, Morris M eds.) Wiley, New Jersey, pp. 557-588 (2007).

9) Hirano M, Maeda K, Shitara Y, Sugiyama Y. Contribution of OATP2 (OATP1B1) and OATP8 (OATP1B3) to the hepatic uptake of pitavastatin in humans. J. Pharmacol. Exp. Ther., 311, 139-146 (2004).

10) Crespi CL, Penman BW. Use of cDNA-expressed human cytochrome P450 enzymes to study potential drug-drug interactions. Adv. Pharmacol., 43, 171-188 (1997).

11) Hirano M, Maeda K, Shitara Y, Sugiyama Y. Drug-drug interaction between pitavastatin and various drugs via OATP1B1. Drug Metab. Dispos., 34, 1229-1236 (2006).

12) Yamashiro W, Maeda K, Hirouchi M, Adachi Y, Hu Z, Sugiyama Y. Involvement of transporters in the hepatic uptake and biliary excretion of valsartan, a selective antagonist of the angiotensin II AT1receptor, in humans. Drug Metab. Dispos., 34, 1247-1254 (2006).

13) Ishiguro N, Maeda K, Kishimoto W, Saito A, Harada A, Ebner T, Roth W, Igarashi T, Sugiyama Y. Predominant contribution of OATP1B3 to the hepatic uptake of telmisartan, an angiotensin II receptor antagonist, in humans. Drug Metab. Dispos., 34, 1109-1115 (2006).

14) Iwatsubo $T$, Hirota $N$, Ooie $T$, Suzuki H, Shimada N, Chiba K, Ishizaki T, Green CE, Tyson CA, Sugiyama Y. Prediction of in vivo drug metabolism in the human liver from in vitro metabolism data. Pharmacol. Ther., 73, 147-171 (1997).

15) Chiba M, Ishii Y, Sugiyama Y. Prediction of hepatic clearance in human from in vitro data for successful drug development. AAPS J., 11, 262-276 (2009)

16) Shitara Y, Horie T, Sugiyama Y. Transporters as a determinant of drug clearance and tissue distribution. Eur. J. Pharm. Sci., 27, 425-446 (2006).

17) Maeda K, Sugiyama Y. Prediction of Hepatic Transporter-Mediated Drug-Drug Interaction from In Vitro Data. Transporters in Drug Development. (Sugiyama Y, Steffansen B eds.) Springer, New York, pp. 121-153 (2013).

18) Watanabe T, Maeda K, Kondo T, Nakayama H, Horita S, Kusuhara $\mathrm{H}$, Sugiyama Y. Prediction of the hepatic and renal clearance of transporter substrates in rats using in vitro uptake experiments. Drug Metab. Dispos., 37, 1471-1479 (2009).

19) Watanabe T, Kusuhara H, Watanabe T, Debori Y, Maeda K, Kondo T, Nakayama H, Horita S, Ogilvie BW, Parkinson A, Hu Z, Sugiyama Y. Prediction of the overall renal tubular secretion and hepatic clearance of anionic drugs and a renal drug-drug interaction involving organic anion transporter 3 in humans by in vitro uptake experiments. Drug Metab. Dispos., 39, 1031-1038 (2011).

20) Watanabe T, Kusuhara H, Maeda K, Kanamaru H, Saito Y, Hu Z, Sugiyama $\mathrm{Y}$. Investigation of the rate-determining process in the hepatic elimination of HMG-CoA reductase inhibitors in rats and humans. Drug Metab. Dispos., 38, 215-222 (2010).

21) Maeda K, Ikeda Y, Fujita T, Yoshida K, Azuma Y, Haruyama Y, Yamane N, Kumagai Y, Sugiyama Y. Identification of the rate-determining process in the hepatic clearance of atorvastatin in a clinical cassette microdosing study. Clin. Pharmacol. Ther., 90, 575-581 (2011).

22) Floyd JS, Kaspera R, Marciante KD, Weiss NS, Heckbert SR, Lumley T, Wiggins KL, Tamraz B, Kwok PY, Totah RA, Psaty BM. A screening study of drug-drug interactions in cerivastatin users: an adverse effect of clopidogrel. Clin. Pharmacol. Ther., 91, 896-904 (2012).

23) Mück W, Mai I, Fritsche L, Ochmann K, Rohde G, Unger S, Johne A, Bauer S, Budde K, Roots I, Neumayer HH, Kuhlmann J. Increase in cerivastatin systemic exposure after single and multiple dosing in cyclosporine-treated kidney transplant recipients. Clin. Pharmacol. Ther., 65, 251-261 (1999).

24) Shitara $Y$, Itoh $T$, Sato $H$, Li AP, Sugiyama $Y$. Inhibition of transporter-mediated hepatic uptake as a mechanism for drug-drug interaction between cerivastatin and cyclosporin A. J. Pharmacol. Exp. Ther., 304, 610-616 (2003).

25) Shitara Y, Hirano M, Sato H, Sugiyama Y. Gemfibrozil and its glucuronide inhibit the organic anion transporting polypeptide 2 (OATP2/OATP1B1:SLC21A6)-mediated hepatic uptake and CYP2C8-mediated metabolism of cerivastatin: analysis of the mechanism of the clinically relevant drug-drug interaction between cerivastatin and gemfibrozil. J. Pharmacol. Exp. Ther., 311, 228-236 (2004).

26) Ogilvie BW, Zhang D, Li W, Rodrigues AD, Gipson AE, Holsapple J, Toren P, Parkinson A. Glucuronidation converts gemfibrozil to a potent, metabolism-dependent inhibitor of CYP2C8: implications for drug-drug interactions. Drug Metab. Dispos., 34, 191-197 (2006).

27) Yoshida K, Maeda K, Sugiyama Y. Hepatic and intestinal drug transporters: prediction of pharmacokinetic effects caused by drugdrug interactions and genetic polymorphisms. Annu. Rev. Pharmacol. Toxicol., 53, 581-612 (2013).

28) Food and Drug Administration (FDA). "Drug Interaction StudiesStudy Design, Data Analysis, Implications for Dosing, and Labeling Recommendations. Draft Guidance. US FDA, Silver Spring, MD, U.S.A.”: 〈http://www.fda.gov/Drugs/GuidanceComplianceRegulatory Information/Guidances/default.htm>, 2012.

29) European Medicines Agency (EMA). "Guideline on the Investigation of Drug Interactions. Final PMP/EWP/560/95, EMA, London.”: 〈http:/ www.ema.europa.eu/docs/en_GB/document_library/Scientific guideline/2012/07/WC500129606.pdf), 2012.

30) Pharmaceuticals and Medical Devices Agency (PMDA). Drug interaction guideline for drug development and labeling recommendations (final draft). PMDA, Tokyo (2014).

31) Ito K, Iwatsubo T, Kanamitsu S, Ueda K, Suzuki H, Sugiyama Y. Prediction of pharmacokinetic alterations caused by drug-drug interactions: metabolic interaction in the liver. Pharmacol. Rev., 50, 387-412 (1998)

32) Ito K, Chiba K, Horikawa M, Ishigami M, Mizuno N, Aoki J, Gotoh Y, Iwatsubo T, Kanamitsu S, Kato M, Kawahara I, Niinuma K, Nishino A, Sato N, Tsukamoto Y, Ueda K, Itoh T, Sugiyama Y. Which concentration of the inhibitor should be used to predict in vivo drug interactions from in vitro data? AAPS PharmSci, 4, 53-60 (2002).

33) Matsushima S, Maeda K, Ishiguro N, Igarashi $T$, Sugiyama $Y$. Investigation of the inhibitory effects of various drugs on the hepatic uptake of fexofenadine in humans. Drug Metab. Dispos., 36, 663-669 (2008).

34) Yoshida K, Maeda K, Sugiyama Y. Transporter-mediated drugdrug interactions involving OATP substrates: predictions based on in vitro inhibition studies. Clin. Pharmacol. Ther., 91, 1053-1064 (2012).

35) Tachibana T, Kato M, Watanabe T, Mitsui T, Sugiyama Y. Method for predicting the risk of drug-drug interactions involving inhibition of intestinal CYP3A4 and P-glycoprotein. Xenobiotica, 39, 430-443 (2009).

36) Noé J, Portmann R, Brun ME, Funk C. Substrate-dependent drug-drug interactions between gemfibrozil, fluvastatin and other organic anion-transporting peptide (OATP) substrates on OATP1B1, OATP2B1, and OATP1B3. Drug Metab. Dispos., 35, 1308-1314 (2007).

37) Soars MG, Barton P, Ismair M, Jupp R, Riley RJ. The development, characterization, and application of an OATP1B1 inhibition assay in drug discovery. Drug Metab. Dispos., 40, 1641-1648 (2012).

38) Izumi S, Nozaki Y, Komori T, Maeda K, Takenaka O, Kusano K, Yoshimura T, Kusuhara H, Sugiyama Y. Substrate-dependent inhibition of organic anion transporting polypeptide 1B1: comparative analysis with prototypical probe substrates estradiol-17beta-glucuronide, estrone-3-sulfate, and sulfobromophthalein. Drug Metab. 
Dispos., 41, 1859-1866 (2013).

39) Shitara Y, Nagamatsu Y, Wada S, Sugiyama Y, Horie T. Longlasting inhibition of the transporter-mediated hepatic uptake of sulfobromophthalein by cyclosporin a in rats. Drug Metab. Dispos., 37, 1172-1178 (2009).

40) Amundsen R, Christensen H, Zabihyan B, Asberg A. Cyclosporine $\mathrm{A}$, but not tacrolimus, shows relevant inhibition of organic aniontransporting protein 1B1-mediated transport of atorvastatin. Drug Metab. Dispos., 38, 1499-1504 (2010).

41) Gong IY, Kim RB. Impact of genetic variation in OATP transporters to drug disposition and response. Drug Metab. Pharmacokinet., 28, 4-18 (2013).

42) Maeda K, Sugiyama Y. Impact of genetic polymorphisms of transporters on the pharmacokinetic, pharmacodynamic and toxicological properties of anionic drugs. Drug Metab. Pharmacokinet., 23, 223-235 (2008).

43) Nishizato Y, Ieiri I, Suzuki H, Kimura M, Kawabata K, Hirota T, Takane H, Irie S, Kusuhara H, Urasaki Y, Urae A, Higuchi S, Otsubo K, Sugiyama Y. Polymorphisms of OATP-C (SLC21A6) and OAT3 (SLC22A8) genes: consequences for pravastatin pharmacokinetics. Clin. Pharmacol. Ther., 73, 554-565 (2003).

44) Iwai M, Suzuki H, Ieiri I, Otsubo K, Sugiyama Y. Functional analysis of single nucleotide polymorphisms of hepatic organic anion transporter OATP1B1 (OATP-C). Pharmacogenetics, 14, 749-757 (2004).

45) Mwinyi J, Johne A, Bauer S, Roots I, Gerloff T. Evidence for inverse effects of OATP-C (SLC21A6) 5 and 1b haplotypes on pravastatin kinetics. Clin. Pharmacol. Ther., 75, 415-421 (2004).

46) Maeda K, Ieiri I, Yasuda K, Fujino A, Fujiwara H, Otsubo K, Hirano M, Watanabe T, Kitamura Y, Kusuhara H, Sugiyama Y. Effects of organic anion transporting polypeptide 1B1 haplotype on pharmacokinetics of pravastatin, valsartan, and temocapril. Clin. Pharmacol. Ther., 79, 427-439 (2006).

47) Nies AT, Niemi M, Burk O, Winter S, Zanger UM, Stieger B, Schwab M, Schaeffeler E. Genetics is a major determinant of expression of the human hepatic uptake transporter OATP1B1, but not of OATP1B3 and OATP2B1. Genome Med., 5, 1 (2013).

48) Generaux GT, Bonomo FM, Johnson M, Mahar Doan KM. Impact of SLCO1B1 (OATP1B1) and ABCG2 (BCRP) genetic polymorphisms and inhibition on LDL-C lowering and myopathy of statins. Xenobiotica, 41, 639-651 (2011)

49) Watanabe T, Kusuhara H, Maeda K, Shitara Y, Sugiyama Y. Physiologically based pharmacokinetic modeling to predict transportermediated clearance and distribution of pravastatin in humans. $J$. Pharmacol. Exp. Ther., 328, 652-662 (2009).

50) Link E, Parish S, Armitage J, Bowman L, Heath S, Matsuda F, Gut I, Lathrop M, Collins R; SEARCH Collaborative Group. SLCO1B1 variants and statin-induced myopathy-a genomewide study. $N$. Engl. J. Med., 359, 789-799 (2008).

51) Voora D, Shah SH, Spasojevic I, Ali S, Reed CR, Salisbury BA, Ginsburg GS. The SLCO1B1*5 genetic variant is associated with statin-induced side effects. J. Am. Coll. Cardiol., 54, 1609-1616 (2009).

52) Donnelly LA, Doney AS, Tavendale R, Lang CC, Pearson ER, Colhoun HM, McCarthy MI, Hattersley AT, Morris AD, Palmer CN. Common nonsynonymous substitutions in SLCO1B1 predispose to statin intolerance in routinely treated individuals with type 2 diabetes: a go-DARTS study. Clin. Pharmacol. Ther., 89, 210-216 (2011).

53) Kalliokoski A, Neuvonen M, Neuvonen PJ, Niemi M. Different effects of SLCO1B1 polymorphism on the pharmacokinetics and pharmacodynamics of repaglinide and nateglinide. J. Clin. Pharmacol., 48, 311-321 (2008).

54) Niemi M, Backman JT, Kajosaari LI, Leathart JB, Neuvonen M, Daly AK, Eichelbaum M, Kivisto KT, Neuvonen PJ. Polymorphic organic anion transporting polypeptide 1B1 is a major determinant of repaglinide pharmacokinetics. Clin. Pharmacol. Ther., 77,
468-478 (2005).

55) Tomalik-Scharte D, Fuhr U, Hellmich M, Frank D, Doroshyenko O, Jetter A, Stingl JC. Effect of the CYP2C8 genotype on the pharmacokinetics and pharmacodynamics of repaglinide. Drug Metab. Dispos., 39, 927-932 (2011).

56) Vormfelde SV, Toliat MR, Schirmer M, Meineke I, Nurnberg P, Brockmoller J. The polymorphisms Asn130Asp and Val174Ala in OATP1B1 and the CYP2C9 allele *3 independently affect torsemide pharmacokinetics and pharmacodynamics. Clin. Pharmacol. Ther., 83, 815-817 (2008)

57) Trdan Lušin T, Stieger B, Marc J, Mrhar A, Trontelj J, Zavratnik A, Ostanek B. Organic anion transporting polypeptides OATP1B1 and OATP1B3 and their genetic variants influence the pharmacokinetics and pharmacodynamics of raloxifene. J. Transl. Med., 10, 76 (2012).

58) Nozawa T, Minami H, Sugiura S, Tsuji A, Tamai I. Role of organic anion transporter OATP1B1 (OATP-C) in hepatic uptake of irinotecan and its active metabolite, 7-ethyl-10-hydroxycamptothecin: in vitro evidence and effect of single nucleotide polymorphisms. Drug Metab. Dispos., 33, 434-439 (2005).

59) Han JY, Lim HS, Shin ES, Yoo YK, Park YH, Lee JE, Kim HT, Lee JS. Influence of the organic anion-transporting polypeptide 1B1 (OATP1B1) polymorphisms on irinotecan-pharmacokinetics and clinical outcome of patients with advanced non-small cell lung cancer. Lung Cancer, 59, 69-75 (2008).

60) Treviño LR, Shimasaki N, Yang W, Panetta JC, Cheng C, Pei D, Chan D, Sparreboom A, Giacomini KM, Pui CH, Evans WE, Relling MV. Germline genetic variation in an organic anion transporter polypeptide associated with methotrexate pharmacokinetics and clinical effects. J. Clin. Oncol., 27, 5972-5978 (2009).

61) Shitara Y, Maeda K, Ikejiri K, Yoshida K, Horie T, Sugiyama Y. Clinical significance of organic anion transporting polypeptides (OATPs) in drug disposition: their roles in hepatic clearance and intestinal absorption. Biopharm. Drug Dispos., 34, 45-78 (2013).

62) Letschert K, Keppler D, König J. Mutations in the SLCO1B3 gene affecting the substrate specificity of the hepatocellular uptake transporter OATP1B3 (OATP8). Pharmacogenetics, 14, 441-452 (2004).

63) Picard N, Yee SW, Woillard JB, Lebranchu Y, Le Meur Y, Giacomini KM, Marquet P. The role of organic anion-transporting polypeptides and their common genetic variants in mycophenolic acid pharmacokinetics. Clin. Pharmacol. Ther., 87, 100-108 (2010).

64) Miura M, Satoh S, Inoue K, Kagaya H, Saito M, Inoue T, Suzuki T, Habuchi T. Influence of SLCO1B1, 1B3, 2B1 and ABCC2 genetic polymorphisms on mycophenolic acid pharmacokinetics in Japanese renal transplant recipients. Eur. J. Clin. Pharmacol., 63, 1161-1169 (2007).

65) Chew SC, Sandanaraj E, Singh O, Chen X, Tan EH, Lim WT, Lee EJ, Chowbay B. Influence of SLCO1B3 haplotype-tag SNPs on docetaxel disposition in Chinese nasopharyngeal cancer patients. Br. J. Clin. Pharmacol., 73, 606-618 (2012).

66) Kiyotani K, Mushiroda T, Kubo M, Zembutsu H, Sugiyama Y, Nakamura Y. Association of genetic polymorphisms in SLCO1B3 and $\mathrm{ABCC} 2$ with docetaxel-induced leukopenia. Cancer Sci., 99, 967-972 (2008).

67) Yamada A, Maeda K, Ishiguro N, Tsuda Y, Igarashi T, Ebner T, Roth W, Ikushiro S, Sugiyama Y. The impact of pharmacogenetics of metabolic enzymes and transporters on the pharmacokinetics of telmisartan in healthy volunteers. Pharmacogenet. Genomics, 21, 523-530 (2011)

68) Yamada A, Maeda K, Kiyotani K, Mushiroda T, Nakamura Y, Sugiyama Y. Kinetic Interpretation of the Importance of OATP1B3 and MRP2 in Docetaxel-Induced Hematopoietic Toxicity. CPT Pharmacometrics Syst. Pharmacol., 3, e126 (2014).

69) "Full Prescribing Information for IMBRUVICA ${ }^{\mathrm{TM}}$ (ibrutinib).": 〈http://www.janssenmd.com/pdf/imbruvica/PI-Imbruvica.pdf〉.

70) Takashima T, Nagata H, Nakae T, Cui Y, Wada Y, Kitamura S, Doi H, Suzuki M, Maeda K, Kusuhara H, Sugiyama Y, Watanabe Y. 
Positron emission tomography studies using (15R)-16-m-[11C]tolyl17,18,19,20-tetranorisocarbacyclin methyl ester for the evaluation of hepatobiliary transport. J. Pharmacol. Exp. Ther., 335, 314-323 (2010).

71) Takashima $T$, Kitamura S, Wada Y, Tanaka M, Shigihara Y, Ishii H, Ijuin R, Shiomi S, Nakae T, Watanabe Y, Cui Y, Doi H, Suzuki M, Maeda K, Kusuhara H, Sugiyama Y, Watanabe Y. PET imagingbased evaluation of hepatobiliary transport in humans with (15R)-11C-TIC-Me. J. Nucl. Med., 53, 741-748 (2012).

72) Shingaki T, Takashima T, Ijuin R, Zhang X, Onoue T, Katayama Y, Okauchi T, Hayashinaka E, Cui Y, Wada Y, Suzuki M, Maeda K, Kusuhara H, Sugiyama Y, Watanabe Y. Evaluation of Oatp and Mrp2 activities in hepatobiliary excretion using newly developed positron emission tomography tracer [11C]dehydropravastatin in rats. J. Pharmacol. Exp. Ther., 347, 193-202 (2013).

73) He J, Yu Y, Prasad B, Link J, Miyaoka RS, Chen X, Unadkat JD. PET imaging of Oatp-mediated hepatobiliary transport of [(11)C] rosuvastatin in the rat. Mol. Pharm., 11, 2745-2754 (2014).

74) Yoshida K, Maeda K, Kusuhara H, Konagaya A. Estimation of feasible solution space using Cluster Newton Method: application to pharmacokinetic analysis of irinotecan with physiologically-based pharmacokinetic models. BMC Syst. Biol., 7 (Suppl. 3), S3 (2013).

75) Fu Q, Li YP, Gao Y, Yang SH, Lu PQ, Jia M, Zhang LR. Lack of association between SLCO1B1 polymorphism and the lipid-lowering effects of atorvastatin and simvastatin in Chinese individuals. Eur. J. Clin. Pharmacol., 69, 1269-1274 (2013).

76) Shabana MF, Mishriki AA, Issac MSM, Bakhoum SWG. Do MDR1 and SLCO1B1 polymorphisms influence the therapeutic response to atorvastatin? A study on a cohort of Egyptian patients with hypercholesterolemia. Mol. Diagn. Ther., 17, 299-309 (2013).

77) Igel M, Arnold KA, Niemi M, Hofmann U, Schwab M, Lutjohann
D, von Bergmann K, Eichelbaum M, Kivisto KT. Impact of the SLCO1B1 polymorphism on the pharmacokinetics and lipid-lowering efficacy of multiple-dose pravastatin. Clin. Pharmacol. Ther., 79, 419-426 (2006).

78) Martin NG, Li KW, Murray H, Putt W, Packard CJ, Humphries SE. The effects of a single nucleotide polymorphism in SLCO1B1 on the pharmacodynamics of pravastatin. Br. J. Clin. Pharmacol., 73, 303-306 (2012).

79) Hedman M, Antikainen M, Holmberg C, Neuvonen M, Eichelbaum M, Kivisto KT, Neuvonen PJ, Niemi M. Pharmacokinetics and response to pravastatin in paediatric patients with familial hypercholesterolaemia and in paediatric cardiac transplant recipients in relation to polymorphisms of the SLCO1B1 and ABCB1 genes. $\mathrm{Br}$. J. Clin. Pharmacol., 61, 706-715 (2006).

80) Lee HK, Hu M, Lui S, Ho CS, Wong CK, Tomlinson B. Effects of polymorphisms in ABCG2, SLCO1B1, SLC10A1 and CYP2C9/19 on plasma concentrations of rosuvastatin and lipid response in Chinese patients. Pharmacogenomics, 14, 1283-1294 (2013).

81) Kalliokoski A, Backman JT, Neuvonen PJ, Niemi M. Effects of the SLCO1B1*1B haplotype on the pharmacokinetics and pharmacodynamics of repaglinide and nateglinide. Pharmacogenet. Genomics, 18, 937-942 (2008)

82) Cheng Y, Wang G, Zhang W, Fan L, Chen Y, Zhou HH. Effect of CYP2C9 and SLCO1B1 polymorphisms on the pharmacokinetics and pharmacodynamics of nateglinide in healthy Chinese male volunteers. Eur. J. Clin. Pharmacol., 69, 407-413 (2013).

83) He J, Qiu Z, Li N, Yu Y, Lu Y, Han D, Li T, Zhao D, Sun W, Fang F, Zheng J, Fan H, Chen X. Effects of SLCO1B1 polymorphisms on the pharmacokinetics and pharmacodynamics of repaglinide in healthy Chinese volunteers. Eur. J. Clin. Pharmacol., 67, 701-707 (2011). 